\title{
The evaluation of a practice change to reduce the risk of type 2 diabetes in a rural primary care practice
}

\author{
Lisa J. Straight \\ West Virginia University
}

Follow this and additional works at: https://researchrepository.wvu.edu/etd

\section{Recommended Citation}

Straight, Lisa J., "The evaluation of a practice change to reduce the risk of type 2 diabetes in a rural primary care practice" (2010). Graduate Theses, Dissertations, and Problem Reports. 2959.

https://researchrepository.wvu.edu/etd/2959

This Dissertation is protected by copyright and/or related rights. It has been brought to you by the The Research Repository @ WVU with permission from the rights-holder(s). You are free to use this Dissertation in any way that is permitted by the copyright and related rights legislation that applies to your use. For other uses you must obtain permission from the rights-holder(s) directly, unless additional rights are indicated by a Creative Commons license in the record and/ or on the work itself. This Dissertation has been accepted for inclusion in WVU Graduate Theses, Dissertations, and Problem Reports collection by an authorized administrator of The Research Repository @ WVU.

For more information, please contact researchrepository@mail.wvu.edu. 
The Evaluation of a Practice Change to Reduce the Risk of Type 2 Diabetes in a Rural Primary Care Practice

Lisa J. Straight, MSN, FNP-BC

Doctoral Research Project submitted to the

School of Nursing

at West Virginia University

in partial fulfillment of the requirements for the degree of

Doctor of Nursing Practice

Nan Leslie, Ph.D., Chair

Lisa Hardman, DNP, BC-ADM, CDE

Robin Whittemore, Ph.D., APRN

Morgantown, West Virginia

2010

Keywords: Diabetes Prevention; Pre-diabetes; Primary Care; Lifestyle Modification

Copyright 2010 Lisa J. Straight 


\begin{abstract}
The Evaluation of a Practice Change to Reduce the Risk for Type 2 Diabetes in a Rural Primary Care Practice
\end{abstract}

\title{
Lisa J. Straight
}

Diabetes mellitus is a growing problem in the United States as well as worldwide. Research has shown that the onset of type 2 diabetes mellitus can be delayed or prevented with lifestyle modifications. One primary care clinic initiated and evaluated a practice change to provide an educational program to at-risk patients to reduce the risk for developing type 2 diabetes mellitus. Three educational sessions followed by bi-weekly telephone contact was provided to

participants. The aim was to reduce parameters placing participants at risk including weight and fasting blood glucose as well as increasing the self efficacy of participants to make lifestyle changes. Statistically significant changes were seen in reductions of weight, body mass index, and fasting blood glucose as well as increases in some measures of self efficacy. The evaluation of the practice change supports the continuation of this program to the primary care population. 


\section{Acknowledgements}

I would like to extend my deepest appreciation to the members of my capstone committee: Dr. Nan Leslie, Dr. Lisa Hardman, and Dr. Robin Whittemore, whose guidance and support have made this project possible. Each one has taught me in this quest and their time and consideration is very much appreciated.

I would like to especially thank my family for their support given to me though this chapter of our lives: To my husband, Micheal, thank you. Your patience and understanding grows stronger through the years and is appreciated. Special thanks to my children: Ashley and Adam, who make all this worthwhile. 


\section{Table of Contents}

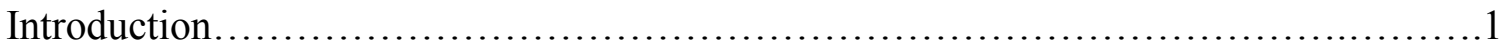

Background and Significance................................................

Literature Review and Synthesis............................................

Project Description....................................................... 13

Theoretical Framework..................................................... 18

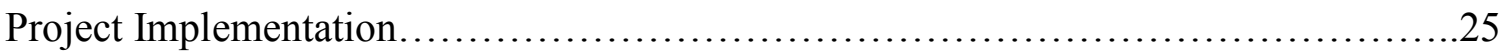

Evaluation Plan............................................................. 30

Results.................................................................... 35

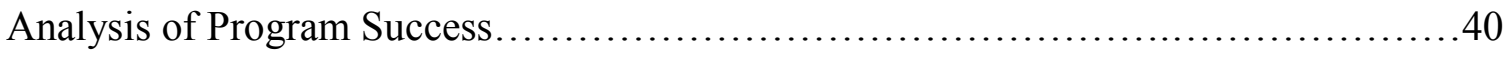

Discussion and Recommendations............................................ 41

Conclusion............................................................. 45

References................................................................. 46

Appendix A: Letter of Agreement............................................52

Appendix B: Recruitment Letter..........................................53

Appendix C: Advertisement Letter for Newspaper...............................55

Appendix D: Flyer for Participation........................................56

Appendix E: Intake Form.....................................................57

Appendix F: Demographics.............................................59

Appendix G: Session One Worksheet.....................................60

Appendix H: Checklist for Class Content.......................................61

Appendix I: Pre-Session One Questionnaire..................................64

Appendix J: Self Efficacy Measures..........................................65 


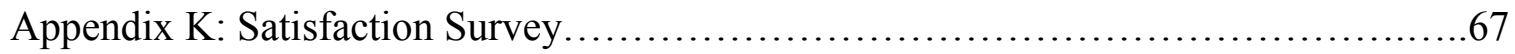

Appendix L: Post Program Survey.............................................68

Appendix M: Results of Pre-Session One Questionnaire............................69

Appendix N: Statistical Analysis for Physiological Parameters...................... 70

Appendix O: Statistical Analysis for Self Efficacy Measures.........................71

Appendix P: Projected Budget............................................. 72

Appendix Q: Mean Values for Group Eating Habits................................74

Appendix R: Data from Post Program Surveys................................... 75 


\section{Introduction}

Diabetes mellitus, specifically type 2 diabetes mellitus (DM), is a disorder of endocrine metabolism affecting multiple body systems. The incidence and prevalence of type $2 \mathrm{DM}$ and pre-diabetes continues to increase steadily to epidemic proportions contributing to significant morbidity, mortality, and financial costs to individuals and society. Research conducted over the last decade has significantly contributed to the body of evidence that type $2 \mathrm{DM}$ can be prevented or delayed in people with pre-diabetes with changes in lifestyle including modest exercise, reduction in dietary fat, and modest weight loss. The Small Steps. Big Rewards. Program (SSBR) was developed to promote these lifestyle modifications for at-risk people. Implementation of the SSBR program at Ritchie County Primary Care, based on the Power to Prevent curriculum, demonstrated that a program of education consisting of three 90 minute group classes was effective at educating and empowering individuals to make lifestyle modifications that could reduce the risk for developing type 2 DM. Physiological parameters of blood glucose, weight, body mass index (BMI), and systolic blood pressure demonstrated statistically significant improvements in the group. The majority of participants documented an improvement in at least one area of healthier eating habits and an increase in either exercise intensity or frequency. Statistically significant increases in self efficacy measures were achieved for eating healthier food and overeating less. While no statistically significant increases in self efficacy related to increased activity were demonstrated, these measures did show improvement after the conclusion of the formal classes as well as nine weeks later at follow up. While no significant decreases were noted with serum lipid levels, these values were decreased slightly. Based on the results obtained, the ease of implementation, and low financial cost to implement, it is recommended that the program be continued at this rural primary care site. 


\section{Background and Significance}

In 2006, diabetes was the seventh leading cause of death in the United States (US) (Centers for Disease Control and Prevention, [CDC] 2008a). This statistic most likely underestimates diabetes' true impact on mortality as death certificates only identify diabetes as a co-morbidity in $35 \%$ to $40 \%$ of the cases. The estimated cost of diabetes in the US, in direct and indirect costs, was $\$ 174$ billion in 2007 with $\$ 58$ million in indirect costs related to disability, work loss, and premature mortality (CDC, 2007a). Recent data released from the CDC (2008b) estimates that the prevalence of type $2 \mathrm{DM}$ in the US has increased by more than three million people over the last two years with 24 million ( $8 \%$ of the population) currently afflicted with the disease. Apart from genetic or ethnic predisposition and advancing age, the primary risk factor for the development of type $2 \mathrm{DM}$ is modifiable. Sedentary lifestyle leading to obesity has been well supported in the literature with obesity affecting approximately $80 \%$ to $90 \%$ of patients with type 2 DM (American Diabetes Association, [ADA], 2008a).

The diagnosis of DM is made with an eight hour fasting blood glucose (FBG) of $\geq 126 \mathrm{mg} / \mathrm{dL}$, a two hour blood glucose $(\mathrm{BG})$ of $\geq 200 \mathrm{mg} / \mathrm{dL}$ following an oral glucose tolerance test or a casual $\mathrm{BG}>200 \mathrm{mg} / \mathrm{dL}$ with the presence of polyuria, polydipsia, and weight loss. A patient with a FBG level of $100 \mathrm{mg} / \mathrm{dL}$ to $125 \mathrm{mg} / \mathrm{dL}$ is said to have impaired fasting glucose (IFG) and is at high risk for subsequently developing type $2 \mathrm{DM}$ if no intervention is initiated (ADA, 2008a).

The CDC also estimates that approximately 57 million people over the age of 20 have pre-diabetes as defined by IFG or impaired glucose tolerance (IGT) and are at risk for developing type 2 DM. The prevalence of pre-diabetes in West Virginia (WV) is estimated to be $1.9 \%$ of the population (CDC, 2007b). Additionally, the prevalence of overweight as a risk factor 
(BMI $25-29.9 \mathrm{~kg} / \mathrm{m} 2$ ) is estimated at $37.7 \%$ and the prevalence of obesity (BMI $30-39.9 \mathrm{~kg} / \mathrm{m} 2$ ) is $30.3 \%$. Within the primary care practice setting under study, the prevalence of type $2 \mathrm{DM}$ among adults is currently estimated at $12 \%$, the prevalence of pre-diabetes at $1-2 \%$, and the prevalence of overweight and obese adults, at risk for type $2 \mathrm{DM}$ is conservatively estimated to be $60 \%$ (Internal data).

Further increasing the risk for type $2 \mathrm{DM}$ for residents of WV includes the relatively sedentary lifestyle of many residents. Data show that residents of WV are less likely to participate in regular exercise than counterparts in other states. While Healthy People 2010 recommends exercise to prevent obesity and diabetes (US Department of Health and Human Services, 2000), data from the CDC (2006) estimate $46.9 \%$ of the residents of WV engage in recommended physical activity (defined as moderate-intensity, enough to cause increase in heart rate) for 30 minutes per day at least five days per week. However, $35.9 \%$ are estimated to engage in insufficient physical activity (more than ten minutes total per week of moderate to vigorous activity but less than recommended) and $17.3 \%$ classify themselves as inactive (less than ten minutes total per week of moderate lifestyle activities). Additionally, when questioned, 27.6\% of those surveyed report no leisure-time physical activity in the previous month. The highest percentage of people reporting limited physical activity were those earning less than $\$ 15,000$ (63.5\%) or having less than a high school education (66.3\%).

\section{Literature Review and Synthesis}

Much research has been conducted that focuses on strategies to delay or prevent the onset of type 2 DM through lifestyle and pharmacological interventions. The purpose of this review was to critically examine the literature related to the effects of exercise and lifestyle modifications on the development or prevention of type $2 \mathrm{DM}$. The question guiding this 
literature search was: In at risk patients, (obese, positive family history, IFG, etc.) what is the effect of lifestyle interventions (diet modification, exercise, and weight loss) on the development of type 2 DM? Additionally, the results of the literature review and synthesis were utilized to support the implementation of a lifestyle modification program in the rural primary care practice in Ritchie County.

\section{Methods}

Prior to implementing the SSBR program, an extensive electronic search of the literature was carried out including the following online databases: the Cochrane Library, MEDLINE, PubMed, CINAHL, Academic Search Premier, Health Source: Nursing/Academic Edition and the National Guidelines Clearinghouse. The last search for relevant studies was conducted on June 28, 2009. Keywords used for searches included combinations of the following: type 2 DM, prevention, exercise, lifestyle modifications, and metabolic syndrome. Searches were restricted to include those articles that were in peer-reviewed journals with abstracts available, published in English and within the last eight years.

\section{Diabetes Prevention}

At the end of the search, articles that were included in the review included three guidelines from the National Guidelines Clearinghouse, three systematic reviews from the Cochrane Library, two additional systematic reviews, two meta-analyses, and seven randomized controlled trials (RCT). To ensure a comprehensive search of the literature, bibliographies of articles retrieved were reviewed to identify further research articles not found in the electronic databases. Each of the guidelines was evaluated with the GuideLine Implementability Appraisal (GLIA). Each of the systematic reviews, meta-analyses and RCTs was critically appraised for 
quality using the criteria established by the Scottish Intercollegiate Guideline Network (SIGN) specific for the methodology of the study.

Analysis of the Literature

Clinical practice guidelines represent the recommendations for practice derived from evidence-based decision making by experts in a particular field and are usually based on extensive review and critique of systematic reviews (Polit \& Beck, 2008). Polit \& Beck, in citing Lewis, hypothesized that, because guidelines for practice are considered expert opinion, different guidelines may offer different or conflicting recommendations. In conducting this systematic review, multiple guidelines for practice related to the prevention of type $2 \mathrm{DM}$ were found in the literature. All the guidelines were supportive of lifestyle modifications as measures to delay or prevent the onset of type 2 DM. For instance, a guideline for exercise for the prevention of type 2 DM has been developed by the American Association of Clinical Endocrinologists (AACE) (2007) and includes weight loss of five to ten percent of total body weight and the prescription of regular physical activity (approximately 150 minutes per week). Both of these interventions are deemed Grade A evidence which means that there is evidence that these intervention improve health outcomes and should be strongly recommended for eligible patients (National Guidelines Clearinghouse, 2010)

To further clarify the concept of physical exercise, the guideline proposed by the Finnish Medical Society Duodecim (FMSD) (2006) recommends moderate intensity exercise during which the heart rate is sustained at $60 \%$ to $75 \%$ of maximum heart rate three to five times a week. Other recommendations from the group for the role of exercise in the prevention of diabetes, adverse effects of aging, and cardiovascular disease include moderate-intensity physical exercise for at least 30 minutes on most, preferably all, days of the week. The group further 
clarifies that the 30 minutes can be accomplished in shorter bouts of exercise throughout the day. The use of a pedometer is beneficial and that 10,000 to 12,500 steps indicate substantial physical activity.

The ADA's clinical practice guideline (2008b) provides recommendations that patients with IGT (Grade A evidence) or IFG (expert consensus) be given counseling regarding weight loss of five to ten percent of body weight as well as increasing physical activity to at least 150 minutes per week of moderate activity such as walking. The ADA also recommends follow up counseling to increase the likelihood of successful weight loss and exercise incorporation (Grade B evidence).

The Cochrane Database of Systematic Reviews has been identified as publishing systematic reviews that meet more rigorous standards than those published in other journals (Polit \& Beck, 2008). Three systematic reviews found in the Cochrane Library (Neild, Summerbell, Hooper, Whittaker, \& Moore, 2008; Norris, et al., 2005; Orozco, et al., 2008), which evaluated type 2 DM prevention, were evaluated for this paper and each concluded that lifestyle interventions were effective in delaying or preventing the onset of type $2 \mathrm{DM}$. Orozco and colleagues concluded that: "educational interventions based on exercise and diet are effective in reducing the incidence of type $2 \mathrm{DM}$ in people presenting with IGT and metabolic syndrome" (p. 20). While diet and exercise combined were found to be the most effective for diabetes prevention with an absolute risk reduction (RR) of 0.63 , there was a lack of research available evaluating the effect of exercise alone in the prevention of type $2 \mathrm{DM}$ as only two studies with a combined sample size of 178 were included. This review notes that studies which utilized exercise alone interventions demonstrated comparable outcomes in terms of diabetes incidence as those which studied diet alone interventions $(n=167)$, however the results were not 
deemed statistically significant for either intervention alone. These studies may have lacked sufficient power to demonstrate statistical significance as other research has supported that either weight loss alone or exercise alone has been effective at reducing the risk for developing type 2 DM. For example, Jeon, Lokken, Hu, and van Dam (2007) completed a systematic review including ten cohort studies that used lifestyle interventions of similar levels of intensity in subjects with comparable type $2 \mathrm{DM}$ risk. The systematic review included a heterogenous population of over 300,000 subjects. The results of the review demonstrated that moderate activity such as brisk walking, cycling, or light gardening, with or without weight loss, reduced the risk for developing type 2 DM by approximately $30 \%$.

Neild et al. (2008) evaluated dietary interventions alone in two RCTs with a total study population of 358 (control and intervention) and found a reduction in the incidence of diabetes in the treatment group (43.8\%) compared to the control group (67.7\%). They also found statistically significant reductions in physiological parameters including: insulin resistance, fasting insulin levels, fasting C-peptide, FBG, BMI, and blood pressure (BP) in the treatment group. Although difficult to completely attribute to the dietary intervention, overall reduction in the risk for type 2 DM in the treatment group after six years was $33 \%$.

A meta-analysis of eight RCTs by Yamaoka and Tango (2005) with a sample size of 5,260 subjects demonstrated that lifestyle education involving diet alone or diet and exercise combined reduced the one-year incidence of diabetes by $50 \%$ compared to controls. These results were essentially repeated by a meta-analysis conducted by Gillies, Abrams, and Lambert (2007). This meta-analysis of seventeen RCTs (including those of Yamoaka and Tango) produced a sample size of 8,084 . The authors concluded from this meta-analysis that the number 
needed to treat (NNT) to see an outcome of the prevention of diabetes with lifestyle interventions was seven compared to eleven as the NNT to prevent diabetes with oral anti-diabetes drugs.

Strong evidence for a combined approach of diet and exercise was identified from a systematic review by Burnet and colleagues (2005). The review sought to determine the effects of lifestyle changes or prophylactic medications on the development of type 2 DM. Included in the review were four major, well conducted RCTs evaluating lifestyle changes to prevent type 2 DM (Diabetes Prevention Program, Diabetes Prevention Study, Da-Qing IGT and Diabetes Study, and the Malmo Feasibility Study). Study characteristics included in the systematic review: were double-blinded, multinational, and produced a sample size of over 4,600 participants. The authors concluded that there is strong evidence for the prevention or delay of onset of type 2 DM through lifestyle changes that include modest weight loss and physical activity (RR 58\% to $63 \%$ ). The prevention of type $2 \mathrm{DM}$ with lifestyle change was even greater than the use of prophylactic pharmacologic therapy with either metformin or acarbose which demonstrated risk reductions of $31 \%$ and $25 \%$ respectively. The group also concluded that individualized counseling helped patients to achieve modest goals. While the studies reviewed used intensive strategies for counseling for effecting lifestyle change, the authors noted that these strategies could be adaptable to the general clinical setting and be provided in brief, office-based visits.

One component of the study by Burnet and colleagues (2005) warrants special attention. A research study (Diabetes Prevention Program Research Group, [DPPRG], 1999), funded by the National Institutes of Health, randomized 3,234 high risk participants to intensive lifestyle modification involving diet and exercise, or blindly to metformin, troglitazone, or placebo groups. The study was completed in 27 clinical centers across the US with minority populations comprising half the total study sample. The primary outcome of the research was the delay or 
prevention of type 2 DM. The study was concluded early as it became apparent that weight loss (7\%), diet (fat intake to less than $25 \%$ of total calories) and lifestyle interventions (150 minutes of exercise per week) were more effective than metformin at delaying or preventing the onset of type 2 DM. The troglitazone arm was suspended due to adverse effects on the liver.

There is evidence to support that weight loss alone, obtained from any means, might serve as a deterrent to the development of type 2 DM. Norris and colleagues. (2005), studied a sample of 5,168 adults from nine RCTs. These researchers noted that weight reduction of $2.8 \mathrm{~kg}$ at 1-year follow up significantly decreased the incidence of type $2 \mathrm{DM}$ in the majority of studies in which this outcome was measured. Although the finding was not statistically significant for improving blood glucose control or lowering BP, the authors concluded that dietary, physical activity, or behavioral interventions that promoted weight loss among persons with prediabetes is important for delaying the onset of type $2 \mathrm{DM}$.

\section{Synthesis}

Type $2 \mathrm{DM}$ is a disease of altered metabolic control that is characterized by a state of hyperinsulinemia and reduced insulin sensitivity resulting in resistance to insulin mediated glucose disposal in the muscle, liver and adipose tissue (ADA, 2008a). It is clearly evident that obesity and a sedentary lifestyle play a significant role in the development of type 2 DM as the majority of people diagnosed with the disorder are clinically obese and/or are relatively sedentary. It becomes evident then that if obesity can be reduced or prevented and/or sedentary lifestyles can be reversed, the incidence of type 2 DM should be reduced.

The goal of this review of the literature was to determine the effects of lifestyle interventions in the prevention of type 2 DM. By examining the practice guidelines, systematic reviews, meta-analyses, and individual RCTs related to diabetes prevention, it is evident that 
lifestyle interventions in the form of exercise and/or dietary interventions with or without weight loss can have significant effects on the development of type $2 \mathrm{DM}$ and may actually prevent the development of type $2 \mathrm{DM}$ in at-risk persons. Exercise and dietary interventions have independently been shown to delay or prevent type $2 \mathrm{DM}$. Weight reduction without exercise has been shown to delay or prevent the onset of type $2 \mathrm{DM}$. There appears to be an additive effect when a combination of interventions is employed. While exercise alone produces marked risk reduction, diet and exercise combined produce an even more pronounced degree of risk reduction.

Lifestyle modifications, which include dietary interventions aimed at restricting energy (calorie restriction), vigorous exercise, and weight loss, may be the most potent strategy for preventing or delaying the onset of type 2 DM (Cox, Burke, Morton, Beilin \& Puddey, 2004). Because type $2 \mathrm{DM}$ is predominately a disease diagnosed in the older, obese patient, strenuous exercise regimens combined with caloric restriction to facilitate significant weight loss may prove difficult for that population. Currently, expert consensus and the research literature advocate modest levels of physical exercise generally described as moderate exertion for 30 minutes on most days of the week for a total of 150 minutes of exercise each week. While walking has been most closely examined for exercise interventions, other forms of moderate to vigorous exercise described in the literature include: bicycling, swimming, resistance training, skiing, jogging, participating in ball games, chopping wood, and clearing brush (Lindstrom, Peltonen, \& Tuomilehot, 2005). Such exercises become viable alternatives in a wide variety of individuals.

Many studies conducted to evaluate the impact of lifestyle interventions on type 2 DM prevention are successful in demonstrating excellent results initially but maintenance of that 
lifestyle intervention with behavior change has proved to be more difficult for participants (Madden, Loeb, \& Smith, 2008). Although declining, risk reduction for the development of type 2 DM years after study completion is still evident from follow up analysis of data and is still greater when compared to those persons who were not exposed to the intervention. One cannot say with certainty if the risk reduction is truly due to the intervention or other factors that occur the longer the time from when the intervention was implemented. It is evident from the literature that contact and follow up with healthcare professionals increase the likelihood of sustained engagement and adherence to the lifestyle intervention. It remains unclear, however, as to the recommendations for the method, frequency, and timing of that follow up.

\section{Evidence to Support Proposed Project}

The intensive lifestyle intervention arm of the Diabetes Prevention Program (DPP) provided intensive "training in diet, exercise and behavior modification skills, frequent support for behavior change; and diet and exercise interventions that are flexible" (DPPRG, 1999, p. 626). The program was delivered with a combination of individual and group interventions with structured curriculum and individual flexibility to assist individuals achieve goals. Case managers met with participants for 16 sessions in the first 24 weeks of the program to deliver the core curriculum of the program. Face to face or telephone contact was completed monthly thereafter. Two supervised, group exercise education sessions were conducted every week to help participants achieve their exercise goals. Data demonstrated a significant reduction in the risk of type $2 \mathrm{DM}$ with these interventions.

While the DPP study demonstrated that intensive, costly interventions that changed behaviors were effective in reducing the risk for developing type $2 \mathrm{DM}$, the emphasis now has shifted to using that knowledge in real world, more cost effective programs; in other words, in 
translating research into practice. After reviewing the literature, several studies were found that tested the protocols and curriculum of the program, attempted to replicate results, and provide further support for the program in various groups and settings.

Pagoto, Kantor, Bodenlos, Gitkind, and Ma (2008) demonstrated that modification of the DPP could be successful at promoting weight loss and improving parameters for the patient with pre-diabetes or metabolic syndrome in a cost-effective way by delivery in a group setting. The program was able to achieve results (weight loss among participants) with reduced implementation costs and shorter duration for the delivery of the intervention (16 weeks). These results were replicated by Amundson et al. (2009) with 70\% of participants meeting exercise goals of 150 minutes per week and $67 \%$ of participants achieving $5 \%$ weight loss (average weight loss of $6.7 \%$ ) in 16 weeks.

Aldana et al. (2006) investigated the application of the DPP protocols over 12 months in a workplace setting, with content delivered in individual or group settings. Participants were permitted to attend sessions during regular work hours and were followed for two years. Statistically significant reductions in weight, BMI, fasting insulin, and lipids along with increases in aerobic fitness were demonstrated during the first year of the study. Although some clinical measures demonstrated reductions in statistical significance after two years, 12 of 22 employees no longer had blood glucose values indicative of pre-diabetes at the conclusion of the study.

A pilot study by Whittemore et al. (2009) sought to test the DPP delivery with nurse practitioners in rural primary care using a modified six-session, six-month program. The condensed delivery involved a total of three hours of in-person support with one hour of telephone support to participants. Education was carried out in the context of regular office hours 
in 20-minute appointments and demonstrated success in helping a low-income, rural population to achieve modest weight loss and improvements in high-density lipoproteins.

While the DPP may be intensive and costly to implement, Ackermann and Marrero (2007) were able to adapt the DPP protocol by delivering the curriculum with lay staff in a group setting at a YMCA facility. The Indianapolis based study demonstrated that the cost to operate the program was between $\$ 275$ and $\$ 325$ per person compared to $\$ 1400$ for the original DPP intervention. Three phases of the project included: the 16-lesson education regarding lifestyle interventions to reduce risk, eight exercise sessions with a training partner, and ongoing maintenance sessions with training groups or partners. Parameters for risk reduction, such as weight loss, were not measured specifically, but the study is significant when one considers that high-risk individuals may be willing to pay $\$ 63$ per month for access to, and participation in, a program similar to the DPP to reduce their risk for developing type 2 DM (Johnson et al., 2006).

These applications of the DPP protocols offered in various delivery formats, with various populations, in various settings, with varying time and monetary commitments by patients and providers continue to add to the body of knowledge for the program. It is expected that the proposed capstone project will have similarly positive results.

\section{Project Description}

The site for the practice change is designated as a Federally Qualified Health Care Center (FQHC) and is located in western WV. Prior to implementation of this program, no formal educational program aimed at assisting patients with risk factors for developing type 2 DM existed in the practice site. The practice change was designed to deliver a modified version of the Power to Prevent program in conjunction with the SSBR program and materials. The SSBR and Power to Prevent programs were developed by the National Diabetes Education Program 
(NDEP) and include easy-to-use, lifestyle educational materials (DPRG, 1999) that assist individuals to safely initiate an exercise and lifestyle modification program to reduce risk. Underlying the program are the findings that type $2 \mathrm{DM}$ can be prevented or delayed in at-risk individuals with the incorporation of moderate weight loss through a low-fat diet and 30 minutes of physical activity on most days of the week (ADA, 2008b; AACE, 2007).

The program was designed to be delivered in three 90 minutes group classes with telephone contact provided with the program director approximately every two weeks until the 12 week follow up. Fasting glucose, weight, BP, and measures of eating habits and self efficacy were measured pre- and post-intervention for each participant. Given the identified need for such a program, the questions being asked are:

Does the delivery of a diabetes prevention program emphasizing lifestyle modification influence at-risk persons to:

1. make changes in lifestyle,

2. enhance self-efficacy to continue those changes,

3. result in reduction of risk factors for the development of type $2 \mathrm{DM}$ ?

\section{Congruence of Project With Mission of Organization}

Ritchie County Primary Care Association (RCPCA), located in Harrisville, Ritchie County, WV is designated as a $\mathrm{FQHC}$ receiving federal funding for service to the medically underserved. It operates primary care practices in Ritchie and Doddridge counties and school based health and wellness centers in Ritchie, Wood, and Pleasants counties. As already mentioned, there is a high prevalence of type $2 \mathrm{DM}$, and a significant number of at-risk patients who are overweight or obese. These estimates constitute a considerable population of patients 
who could benefit from prevention-based interventions. Currently, there is no formal diabetes education or prevention program for the organization at any of its practice sites.

The mission of RCPCA is as follows:

The goal of Ritchie County Primary Care Association is to insure that all residents in the service area have access to quality health care on a nondiscriminatory basis regardless of race, color, sex, creed, disability, national origin or ability to pay.

The vision of RCPCA is as follows:

The vision of Ritchie County Primary Care Association is to continue to expand the services and access to healthcare of the citizens of the service area emphasizing health promotion and disease prevention until all citizens have access to quality healthcare.

This program is compatible with the mission and vision of RCPCA, in that type 2 DM prevention strategies are being proposed for all patients without discrimination. The major emphasis of the SSBR program is the prevention of type 2 DM in at-risk individuals through healthy eating and physical activity (NDEP, 2005). The program emphasizes health promotion congruent with the vision statement of the organization.

\section{Stakeholders}

Key stakeholders are those individuals or groups who are impacted by and can impact the success or failure of an endeavor. The RCPCA is governed by a board of directors with administrative duties carried out by an administrator and chief financial officer. The medical director is responsible for review of policies and procedures related to patient care, in addition to primary care practice duties. In additional to the medical director, two primary care physicians 
and three family nurse practitioners provide health care to the patients of the practice. Office nursing staff includes licensed practical nurses and medical assistants who have a vital role in the care of the patients, as well as providing a communication link between providers and patients.

Outside stakeholders who are important to the success of the program include the patient and family members who will participate in the program. Additionally, civic or community leaders can play a pivotal role in the success of the program through advertising and participating in recruitment. Governmental and other payer agencies, which are the source of revenue from reimbursement for services, are also important to the success of the program. Additional potential funding sources include pharmaceutical and equipment representatives, community agencies, and charitable organizations.

\section{Resources}

Key personnel for assisting in implementing this capstone project included the administrator of RCPCA who serves a pivotal role in distribution of labor and resources. The administrator fully supported this practice change project (Appendix A) and permission was obtained for use of the facilities, copier, and incentives. Additionally, support was provided for the use of office staff who directed patients to appropriate areas, ensured uninterrupted classes, and ensured proper billing procedures were followed for program participants. Nursing staff was helpful in obtaining data including BP measurements and blood sample collection. Technological resources included the electronic health record utilized by the organization. As already stated, patients were identified for inclusion in the project by seeking patients meeting certain diagnostic codes. Sales representatives of blood glucose monitors served as a resource for the project with donations to assist patients in meeting goals. By providing portion-control plates, sales 
representatives provided the patients with tools needed to make lifestyle changes as well as incentives to make the program more appealing to participants.

\section{Strengths and Weaknesses of the Program}

Strengths of the program include the low cost and ease of implementation. The written materials have been developed by the NDEP for reproduction as needed at no cost. The National Diabetes Information Clearinghouse (NDIC, 2005) Fact Sheets are written at a $10^{\text {th }}$ grade level and the Easy-to-Read booklets are written at a $4^{\text {th }}$ or $5^{\text {th }}$ grade reading level.

The program is grounded in empirical evidence as to the benefits to the patient in terms of risk reduction. The program is relatively easy for participants to initiate and maintain with a minimum of time commitment for educational visits. The program can be implemented during the clinic's regular business hours and does not require the addition of any new staff. Staff training related to identification and referral of patients to the program, assisting in collecting data, and contacting patients for follow up can be completed relatively easily.

Implementation of the program for DM prevention can provide the organization with the opportunity to expand its services by offering reimbursable group education. In addition, by offering a unique service to the local area, the patient population base can be expanded which will further build the practice. The emphasis on health promotion and DM prevention has the potential to foster other health promotion programs, thus placing the organization in a favorable light with the community. This, in turn, might encourage additional patients to seek health care from the practice. The emphasis on health promotion and disease prevention also allows the organization to apply for multiple prevention grants, which could provide funding for additional services. 
Weaknesses of the program include the repeated office visits for education. Additional travel may impede the participation of some patients due to issues with transportation and the increased demand placed on their time. Additional patient costs for follow up labwork may be incurred in implementing the program. Because of RCPCA's FQHC status, income guidelines are in place for reduced payments for services including labwork. Billing for patient services will be completed for allowable charges, but additional charges for laboratory tests and visits may still prove to be cost-prohibitive for some patients.

Potential threats to implementation of the program include those related to patient participation. The program, although emphasizing small behavior changes, could be perceived by patients as too time consuming or too difficult and preclude their participation in the program. Even though it was not anticipated that the program will be cost prohibitive for the organization to implement, difficulties might have arisen if the program was perceived as contributing to revenue losses from lowered patient encounters that might result from the nurse practitioner conducting education. Furthermore, lack of support from nursing staff in the organization related to perceived interference with normal duties could have created difficulties with implementation.

\section{Theoretical Framework}

While research such as the DPP has shown that regular physical exercise is efficacious in reducing the incidence of type $2 \mathrm{DM}$, the majority of patients who are at highest risk for developing type 2 DM do not engage in regular physical activity (Morrato, Hill, Wyatt, Ghushchyan, \& Sullivan, 2007). Increasing self-confidence and motivation of these individuals increases the probability for the success of the SSBR program in this vulnerable population. It becomes important then that the implementation of any program such as SSBR be grounded in a theory that has shown to be effective at increasing self-confidence and motivation. 


\section{Social Learning Theory}

Several theories from nursing and the social sciences have been proposed and tested in various populations related to health promotion and what motivates individuals to incorporate healthful behaviors into their lifestyles. One of the pioneers in explaining how health behavior is shaped and influenced was Albert Bandura who is credited with the development of the Social Learning Theory (SLT). Social Learning Theory, which has also been referred to as Social Cognitive Theory (SCT), (Nieuwenhuijsen, Zemper, Miner, \& Epstein, 2006) attempts to explain how the interaction of environment, behavior and cognition of self and personal values interact together in a reciprocal manner to shape a person's subsequent behavior (Bandura, 1997).

Bandura's early work in the late 1960s (Price \& Archbold, 1995) focused on the concept of modeling as a major tenet of his SLT. Modeling occurs when individuals change their behavior based on the observed behaviors of another individual or group that is found to be interesting. An individual, if properly motivated, observes the behavior, remembers the behavior and then reproduces that behavior in his or her own life. As SLT evolved, Bandura (1997) added concepts of self-observation, judgment, and self-efficacy as important tenets for behavior changes. The updated theory postulates that an individual, through self-observation, acknowledges the desired behavior while judging self in relation to a standard, such as a model, comparing the presence or absence of the desired behavior (Lev \& Owen, 2000). Self-efficacy is correlated with the level of self-confidence the individual feels in relation to their ability to carry out the desired behavior. A person who feels capable and confident to complete the desired behavior will experience a high degree of self-efficacy. The theory is based on the assumption that an individual, when provided with information and the tools needed for self evaluation, will 
be able to determine a course of action to improve or promote health and incorporate health promoting behaviors into his or her lifestyle (Bandura, 1997).

\section{Tenets of the SLT and Its Application with Small Steps. Big Reward. Program}

Two major concepts in the SLT developed by Bandura (1997) related to self-efficacy theory include self-efficacy expectations and outcome expectations. Self-efficacy expectations are defined as the individual's personal judgments about his or her ability to accomplish a given task. In other words, how confident the individual is that he or she will be able to change behavior to improve health. An individual with a high level of self-efficacy is confident in his or her ability and has high self-efficacy expectations. Behavior is adopted or rejected based upon the perceived effort required to initiate the behavior and the level of persistence needed to sustain the behavior. One of the major underlying themes of the SSBR program is that unrealistic goals often lead to failure and frustration for both individual and health care provider. Significant risk reduction for developing type $2 \mathrm{DM}$ can occur with incorporation of modest levels of physical activity promoting modest weight loss of just five to seven percent of total body weight (NDEP, 2005). Therefore, framing weight loss in this perspective for the individual is likely to increase his or her self-confidence in achieving that goal.

The second major concept is that of outcome expectations. Outcome expectations refer to the individual's personal judgments about the consequences to self if the behavior change is incorporated (Bandura, 1997). The behavior is likely to be incorporated into the individual's lifestyle if that behavior is perceived as truly beneficial, in other words, if the individual has high outcome expectations. If the individual does not see the benefit to the behavior or feels that the effort required to carry out the behavior is too strenuous or taxing for the perceived benefit, outcome expectations are lower and there is a decreased likelihood of the incorporation of the 
behavior into the person's life. The behavior is more likely to be adopted by the individual if the behavior change is not seen as overwhelming and difficult to achieve while providing benefit to the individual. The DPP (1999) showed that lifestyle interventions resulting in modest weight loss of five to ten percent of total body weight were capable of reducing the incidence of type 2 DM by $58 \%$. The SSBR program includes tools patients can use to assess their personal risk for developing type $2 \mathrm{DM}$ and educates the patient about the well-documented benefits of incorporating the lifestyle changes. Information provided by the program emphasizes initiating a safe, gradual walking program that is increased in time and intensity at the patient's own pace and tolerance (NDEP, 2005).

Social Learning Theory also postulates that an individual's confidence level is affected by information sources. Information collected by the individual is obtained from enactive attainment, vicarious experiences of observing others, feedback and persuasion from others, and physiological cues and feedback. Mastery through enactive attainment is the most influential of all the self-efficacy sources (Bandura, 1997) and the best way to increase self-efficacy using enactive attainment is through extensive practice and providing time for mastery of simple skills before more complex skills are undertaken (Shortridge-Baggett, 2001).

Individuals can increase their sense of mastery of a skill by setting reasonable goals and develop a heightened sense of self-confidence and self-efficacy when those goals are achieved (Bandura, 1997; van der Laar \& van der Bijl, 2001). The SSBR program has at its heart the premise that small, achievable goals are set by the individual and that achievement of those goals serves as an impetus to continue the behavior. Written material provided with the program include suggestions for getting in exercise at work or in daily activities to meet goals and increase motivation, thereby raising self-efficacy. The program also emphasizes recording 
activity completed and intake of food so individuals may see and monitor their progress towards meeting their goals.

Vicarious experience, a second factor affecting an individual's sense of self-efficacy involves learning about personal abilities through the observation of others (Bandura, 1997). This can be accomplished through the use of videos, group role-playing and observation of a vicarious model who could be a peer, significant other or health care provider (Smith \& West, 2006). The project emphasizes group counseling and was conducted by positive role models who value physical exercise and weight control.

Verbal persuasion has been found to be the most commonly used source of information for self-efficacy (van der Laar \& van der Bij1, 2001). Positive feedback for the at-risk patient from a credible, trustworthy, and knowledgeable person (Shortridge-Baggett, 2001) increases the probability that self-efficacy will be increased and that the desired behavior will be continued. In implementing this project, individuals have initial face-to-face contact and follow-up contact by telephone. As mentioned earlier, this contact with healthcare professionals is a critical element for assisting individuals to achieve their goals and increase their confidence and self-efficacy.

Exercise and dietary changes can result in lowered FBG, reduced weight, reduced blood pressure, and reduced feelings of anxiety (CDC, 2009). The project allows for the measurement of these physiological parameters, the fourth source of information regarding self-efficacy (Bandura, 1997), thereby increasing the self-confidence and self-efficacy of the individual as these values change. The following table summarizes the implementation of the SSBR program using the SLT.

\begin{tabular}{|l|l|l|}
\hline Major Tenet of SLT & Application to SSBR & Major Tenet of SLT \\
\hline Self-efficacy expectations & & Outcome Expectations \\
\hline $\begin{array}{l}\text { Perceived benefit to initiate } \\
\text { behaviors }\end{array}$ & $\begin{array}{l}\text { Small changes in diet, exercise } \\
\text { and weight loss can contribute }\end{array}$ & $\begin{array}{l}\text { Beneficial activity but not } \\
\text { overwhelming }\end{array}$ \\
\hline
\end{tabular}




\begin{tabular}{|l|l|l|}
\hline & $\begin{array}{l}\text { to reduced risk for developing } \\
\text { type 2 DM }\end{array}$ & \\
\hline $\begin{array}{l}\text { Level of persistence needed to } \\
\text { sustain the behavior }\end{array}$ & $\begin{array}{l}\text { Set reasonable, achievable } \\
\text { goals. Reduce frustration }\end{array}$ & $\begin{array}{l}\text { Enactive attainment: mastery } \\
\text { of skills }\end{array}$ \\
\hline & $\begin{array}{l}\text { Use of logs/diaries to } \\
\text { document progress to meeting } \\
\text { goals }\end{array}$ & \\
\hline & $\begin{array}{l}\text { Use of group meetings: } \\
\text { opportunity to share } \\
\text { experiences, resources, } \\
\text { support }\end{array}$ & Vicarious experience \\
\hline & $\begin{array}{l}\text { Healthcare provider leading } \\
\text { group meetings. Opportunity } \\
\text { to share information, ask } \\
\text { questions }\end{array}$ & Verbal persuasion \\
\hline & $\begin{array}{l}\text { Blood pressure, weight, FPG } \\
\text { reductions as well as increased } \\
\text { sense of well-being, lessened } \\
\text { depression, more energy }\end{array}$ & $\begin{array}{l}\text { Physiological cues and } \\
\text { feedback }\end{array}$ \\
\hline
\end{tabular}

Effects of Enhanced Self-Efficacy

Research has expanded beyond why people fail to participate in programs of health promotion to also include foci related to principles of illness prevention, promotion of health and well-being, and exploring ways to increase the confidence of people to incorporate health promoting or illness preventing behaviors into their lifestyle. Social Learning Theory has been utilized as a conceptual framework for widely diverse populations experiencing widely varying health promotion and illness prevention needs. This extensive reference base represents the wide range of applicability of the theory across different populations.

The wide-ranging literature on SLT and the concept of self-efficacy demonstrates overwhelmingly that the health interventions incorporating self-efficacy principles result in better treatment outcomes than those that are not based on self-efficacy frameworks (Smith \& West, 2006). Numerous studies identified by Lev and Owen (2000) report that increased selfefficacy leads to increased quality of life, improved symptoms, and less depression. 
Enhanced self-efficacy has been shown to promote adherence to recommended medical regimens including diet and exercise (Senecal \& Nouwen, 2000) and numerous studies reported by Parrish, Kosma, and Welsch (2007) identified enhanced self-efficacy as the most important indicator for engagement in physical exercise. More specific to this project is a study by Zizzi et al. (2006) which demonstrated that among 1,239 Appalachian adults, readiness to participate in exercise and self-efficacy were highly significant predictors of subsequent physical activity behaviors, particularly at moderate to vigorous levels of exercise.

The goal of the program is to provide education and support to individuals at risk for developing type $2 \mathrm{DM}$ to prevent the development of the disease. The program empowers an individual to incorporate disease prevention interventions into his or her lifestyle. This will enhance the individual's sense of control. This increased sense of control that individuals experience with enhanced perceptions of self-efficacy has been shown to reduce psychological distress and physical illness (Throits, 1995).

Bandura (1997) concluded that confidence in one's ability to perform behaviors and master self-management by incorporating relevant behavior in a particular situation has a major impact on adjustment to illness and incorporation of health promoting practices. This mastery of self-management and increased self-efficacy allows individuals to solve problems, make decisions, and construct action plans to achieve well-defined and achievable goals (Jones, 2006). All of these activities are relevant to the program.

Quantitative measurement of self-efficacy attempts to evaluate pre-intervention and postintervention levels of perceived self-efficacy. These measurement tools allow for testing interventions designed to help participants believe in the benefits of the behavior, and identify challenges to be faced and obstacles to be overcome when incorporating the behaviors into their 
lifestyle (Resnick, 2003). The SSBR Power to Prevent curriculum includes questionnaires for measurement of knowledge, attitudes, and confidence of participants in terms of their level of physical activity and eating habits as well as their confidence in making positive changes in diet and physical activity in congruence with measurement of self efficacy. The publications of the SSBR program are written at an eighth grade reading level and have been shown to be valid and reliable.

\section{Project Implementation}

While the DPP study demonstrated that intensive, costly interventions that changed behaviors were effective in reducing the risk for developing type $2 \mathrm{DM}$ this level of intensity may not be feasible for implementation in the rural primary care setting. As previously outlined, modification of the DPP delivery including condensed delivery and delivery in group settings has been successful at promoting weight loss and improving parameters for the patient with prediabetes or metabolic syndrome in a cost-effective way. This practice change was designed to be practical for implementation and continuation in the rural primary care practice setting for the organization, the healthcare providers, and the patient participants.

\section{Timeline for Implementation}

The timeline for the project was divided into pre-intervention, intervention, and postintervention sections. It was hoped that the project could be initiated in May 2009 and offer potential participants free entry into RCPCA's 5K health walk/run in August as an incentive to participate in the program. This $5 \mathrm{~K}$ participation was viewed as a reasonable goal for participants to strive to meet. However, Institutional Review Board approval was not obtained until midsummer and the first class was not offered until August, after the race. Subsequent groups of participants were not able to start the program until late September which put the completion 
date for 12-week follow up at early to mid December. These participants were encouraged to participate in a local Turkey Trot $5 \mathrm{~K}$ as an alternative and several opted to participate. It was initially hoped that the program could be completed prior to the holiday season. All data collection was completed by December 15, 2009.

Eligibility and Recruitment

After obtaining approval from the Institutional Review Board of West Virginia University, the Board of Directors of the facility and the administrator of the facility (Appendix A), a search was conducted of the electronic health system of the facility to identify patients who met the inclusion criteria. Inclusion criteria included a FBG level of $100 \mathrm{mg} / \mathrm{dL}$ to $125 \mathrm{mg} / \mathrm{dL}$, aged 18 to 60 , identified within the organization within the last six months. Patients were identified from a search of the Medcin Electronic Health System using the diagnosis codes for IFG and metabolic syndrome. Other diagnostic codes utilized to identify potential patients included HTN, obesity, and family history of diabetes. An individual review of the medical records of patients who recently completed the Cardiac Clinics and Wise Woman clinics held at the facility identified those at-risk individuals for these visits were coded as screening visits without medical diagnoses.

Once identified as having IFG by laboratory evaluation, the medical record was evaluated for additional risk factors for type $2 \mathrm{DM}$. The potential participants had at least one other risk factor for diabetes. Such risk factors include sedentary lifestyle, obesity with BMI greater than $25 \mathrm{~kg} / \mathrm{m} 2$, a history of gestational diabetes, hypertension, hypertriglyceridemia with lowered HDL, or a positive family history of type $2 \mathrm{DM}$. Those persons already diagnosed with diabetes, or who meet inclusion criteria but had untreated or unstable cardiovascular conditions were excluded from participation. 
The result of this search yielded 43 eligible patients. A recruitment letter (Appendix B) with a Flesch-Kincaid defined eighth grade reading level, was mailed to each patient who met inclusion criteria, along with a stamped, self-addressed envelope to return the acceptance or rejection letter. Classes were offered on three different days of the week (Tuesday evening, Thursday or Saturday morning) to accommodate various schedules. Patients were offered the option of choosing which class time to attend or changing classes if needed. Five affirmative responses and one declining response were received initially. Attempts were made with telephone calls to contact those eligible participants who did not return responses to recruit them to participate. No further participants were recruited with the telephone solicitation. Six additional participants were included after hearing of the program from office employees and who underwent screening and demonstrated IFG.

Due to the low participation of the patients in the initial offering, the program was offered again in conjunction with the organization's school based health centers. Participants were recruited via email, newspaper advertisements (Appendix C), and flyer (Appendix D) describing the program. Participants were then screened for diabetes with FBG levels and included if inclusion criteria were met for participation. Two participants with elevated blood glucose over $126 \mathrm{mg} / \mathrm{dL}$ ( 155 and $146 \mathrm{mg} / \mathrm{dL}$ ) were included, with permission from their healthcare providers who agreed to attempt lifestyle modifications prior to initiating pharmacologic therapy for new onset diabetes. Those persons responding to the advertisement who did not meet inclusion criteria were still invited to participate in the program as guest participants. The classes were conducted for three groups and resulted in a total of 25 eligible participants and 13 guest participants. Twenty-two of the 25 eligible participants (14 women and eight men) completed the program while nine guest participants completed the program. Completion of the program was 
defined as completing post-program labwork and self-efficacy questionnaires. Pertinent data including contact information, current medications, and whether participants had ever been told not to participate in exercise were recorded on the intake form (Appendix E). One participant was started on levothyroxine during the course of the program: otherwise, all participants' medication regimens were unchanged. Ten of the 22 participants were between the ages of 41 and 50 (See Table 1, Appendix F for number of participants by age).

\section{Class Content and Format}

The program was offered in three, 90 minute, weekly sessions. At the first session, participants were provided with pedometers, portion control plates, a notebook with the SSBR food and activity logs for 12 weeks of record keeping as well as the SSBR Fat and Calorie counter. Participants identified his or her personal risk factors for developing type $2 \mathrm{DM}$ (Appendix G) and calculated recommended five and ten percent weight loss goals.

Recommended weight loss was one to two pounds per week. Fat and calorie restrictions based on current weight as recommended by the NDEP were established with each participant. A lecture format with open discussion in the group was used to deliver information and handouts were provided covering topics such as healthier eating habits, reading food labels, portion control, and reducing fat and cholesterol. Handouts and discussion related to healthier eating and beginning an exercise program were included in class one and participants were encouraged to use the pedometer as a method of objectively measuring activity with a recommendation to build up to 10,000-12,000 steps per day.

The second and third sessions continued with a modified, condensed, Power to Prevent curriculum which included topics such as eating out, meal planning, social situations, and recommendations to deal with stress and slips in lifestyle changes. Participants were encouraged 
to write down a goal for healthier eating and activity at the conclusion of each weekly session. Each class for all groups was conducted based on a pre-determined checklist (Appendix H) and utilized the same power point presentation.

Follow up contact and encouragement has been shown to be beneficial in helping individuals make and continue with lifestyle modifications to improve health. Support for participants was provided with telephone communication that was attempted for each participant approximately every two weeks following the third class. This communication was designed to ascertain the participant's success with meeting his or her established goal for the week, to provide ongoing support and encouragement with incorporating lifestyle changes, and to help participants with any concerns or questions related to the program implementation. A minimum of two telephone calls were successfully completed to all but three participants (86.4\%) for whom messages were left on answering machines with contact information to return call for support as desired. Fifty nine percent of participants were successfully contacted via telephone at least three times in the nine-week follow up period.

\section{Data Collection}

Physiological parameters including height, weight, BP measurement, and BMI calculations were collected prior to the first class and at the conclusion of a nine-week follow up with the program lasting 12 weeks from first class to post-program data collection. All data were recorded including attendance to sessions and verbal statements with telephone follow up on the program Intake Form. Questionnaires from the Power to Prevent program (Appendix I) were utilized to elicit participants' reasoning for attending the program. The program also utilized program questionnaires (Appendix J) to measure current lifestyle habits related to eating and physical activity and determine participants' self-efficacy measurements for dietary and physical 
activity changes. These questionnaires were completed prior to the first class, at the conclusion of the third class, and at the 12-week follow up. A satisfaction survey (Appendix K) was completed by participants at the end of the third class and a post-program survey (Appendix L) was completed at 12 -week follow up.

\section{Evaluation Plan}

The overall objectives of the project were to implement a program for patients at-risk for type $2 \mathrm{DM}$, and to educate, and empower them to make necessary lifestyle interventions to reduce risk of developing the disease. The program was designed to benefit the at-risk participant, not only physically, but psychologically as well. In addition, it was hoped that the organization would continue this program as a billable service. Evaluation of the program and its effectiveness can be done in terms of contextual factors, factors related to implementation, and outcomes achieved.

\section{Contextual Factors}

Given that this project is a practice change within this $\mathrm{FQHC}$ facility, it is important to consider factors related to the setting, the organization, and the participation of those involved. The implementation of this education program provided the organization with information related to the need for such a program as the incidence and prevalence of IFG and pre-diabetes within the practice was scrutinized. More importantly was the realization that more rigorous testing and screening needs to occur as several participants were unaware of their pre-diabetic status prior to testing.

It is estimated that approximately 25 to 30 hours were necessary for planning the program and developing the powerpoint presentations to be used in the classes. Additionally, six hours were used for printing and binding of the written materials. Approximately two hours were 
needed for each class including preparation and clean up time while implementing the program. Now that the program has been developed, time commitments for subsequent groups will be significantly reduced and primarily devoted to printing materials and presentation of educational content. Consideration can be given to developing a script for use with each group that would allow other providers or lay persons to deliver the program if interested.

Implementation of the program demonstrated to the organization that the program is feasible to offer to the pre-diabetic population but could also be offered to obese individuals or patients who simply want information related to healthier lifestyle habits. Indeed, given the difficulty in recruiting participants from the initial patients diagnosed with pre-diabetes, it would behoove the organization to expand the intended audience.

A satisfaction survey was given to participants and guests at the end of the third class to elicit feedback related to contextual factors. Twenty seven surveys were returned with 16 of the respondents reporting "very satisfied" with all aspects of the program including the number, times, and setting for the classes. Nine survey respondents reported either "very satisfied" or "somewhat satisfied" with all aspects including number, times, and setting for the classes. Only one survey respondent reported "not satisfied" with the number of classes requesting to meet more often. One hundred percent of respondents would recommend the program to a friend or relative and some noted that they already had done so. Participants were encouraged to provide suggestions for improving the setting and overall experience at the facility and feedback included three comments for expanding the number of classes offered. Suggestions were made to offer the program to specific groups but no specific suggestions for changes in class content or presentation methods were noted. Individual comments included: 
- Thank you. This has been wonderful. I'm very anxious about “being on my own”. Can't wait until we meet again.

- $\quad$ Try to set up classes for Simontons/Schads

- Great incentives

- I think this is a great, helpful program and hope it will continue to be offered.

- Brilliant. Thank you!

- I would like to see this program offered to teenagers.

- Instructor kept my attention and presented the information clearly.

- I learned a lot from attending and believe it is a well needed class.

\section{Implementation Factors}

The logistics of recruitment demonstrated that, as the program proceeded, providers were more likely to document a diagnosis of IFG for patients in the organization and that the electronic medical record was an efficient method for identifying eligible participants. Attendance at each class was evaluated and demonstrated that participants were likely to attend all three classes: $75 \%$ of participants attended all three sessions while $21.6 \%$ attended two of the three sessions. Illness and family commitments were cited most frequently as reasons for absences to class. Participants were offered make-up classes but only one participant chose to do so.

The "pre-session one questionnaire" (Appendix I) from the Power to Prevent program was utilized to identify participants' and guests' goals and expectations for participating in the program. Results are presented in Table 2, Appendix M. These results indicated that participants were interested in weight loss through improved eating habits and physical activity. While important to several participants, diabetes prevention and group support were viewed as lesser 
goals. This information can be used in subsequent classes by placing emphasis on weight loss, healthier cooking methods and eating habits, and encouragement of physical exercise.

The satisfaction survey elicited positive feedback related to instructor/presenter effectiveness as well as class timing and frequency. After completing the individual classes, it is recommended that the length of time required for each class be 90 minutes unless additional classes are added for subsequent programs at which time the material to be presented could be given in shorter, more numerous classes. Given that some participants provided feedback that additional classes should be added, subsequent programs could elicit group consensus at the onset related to whether participants are interested in the addition of classes or meetings.

Feedback from the satisfaction survey was very positive for the program materials and incentives however the majority of participants reported "never" or "rarely" (on post-program survey) to using the pedometers for measurement of physical exercise even though $99 \%$ of participants reported walking as the preferred method of exercise.

\section{Outcome Factors}

The SSBR program using the Power to Prevent curriculum is designed to provide participants with the knowledge and tools to make lifestyle modifications which will improve their health and reduce the risk of developing type 2 DM (NDEP, 2005). A major objective of this project was to reduce the risk for type $2 \mathrm{DM}$ in at-risk patients. Outcome measures related to this objective include changes in physiological parameters. The primary physiological parameters that were evaluated in this program included FBG, weight, BMI, and BP with secondary measurements of serum lipids (total cholesterol, high density lipoproteins [HDL], low density lipoproteins [LDL], and triglycerides) if available. These measures were obtained from fasting blood specimens prior to the first class and 12 weeks after the first class. Statistical 
analysis using pre- and post-education data was completed looking for statistically significant changes $(p<0.05)$ in FBG, weight, BMI, BP, LDL and HDL cholesterol, and triglycerides.

\section{Data Analysis}

Statistical analysis of data was completed using the SPSS computer software. Given the limited sample size obtained with the project, most tests were completed using non-parametric statistical analysis. Although parametric tests are more powerful than non-parametric tests, nonparametric tests are indicated for data that are markedly nonnormal or in cases of small sample size such as with this project (Polit \& Beck, 2008). Blood pressure data were shown to be normally distributed and so paired $t$ tests were done on this data. Data for weight, BMI, and FBG were not normally distributed and therefore, nonparametric analysis was completed for these variables. Statistical significance was established at $p=.05$. Table 3, Appendix N summarizes the group mean and the statistical method used for each variable studied and the corresponding statistical value.

In considering weight and BMI measurements for the participants, both measures demonstrated statistically significant reductions at $p<.000$. The group's mean for weight prior to beginning the program was 221.14 pounds with a group mean BMI of 35.31 . The group mean at the conclusion of the program was 211.05 pounds with a group mean BMI of 33.45. A total of 188 pounds was lost by the participants, an average of ten pounds per participant. Eighteen of 22 participants (82\%) were able to achieve two percent weight loss while $41 \%(9 / 22)$ achieved five percent weight loss and four participants (18\%) were able to achieve ten percent weight loss. Only one participant gained weight during the program however his fasting glucose dropped $46 \mathrm{mg} / \mathrm{dL}$ to normal levels with his reported increase in exercise. 
Fasting plasma glucose for the participants averaged $115.32 \mathrm{mg} / \mathrm{dL}$ pre-program and this mean dropped to $98.14 \mathrm{mg} / \mathrm{dL}$ at the 12 -week conclusion. This reduction was statistically significant at $p<.000$. Only one participant's glucose rose at the 12 -week follow up despite a 16-pound weight loss but she was experiencing an acute illness (strept throat) at the time of follow up.

Self-efficacy has been identified as a strong predictor of starting and maintaining healthpromoting activities. Self-efficacy measures developed for use with the Power to Prevent curriculum were evaluated prior to the first class, at the conclusion of the third class, and at the time of follow up, 12 weeks after the first class. Repeat measures ANOVA is frequently used to measure the same participant at three times and evaluate if the variable changes over time. However, given the small sample size, a nonparametric test was conducted on this data. The Friedman test was utilized for comparing data at three time points: initial, three-weeks, and program conclusion, evaluating differences in self efficacy measures as a result of the classes. Wilcoxson Signed Ranks Test was utilized to compare data at two points: initial and program conclusion at 12 weeks. Table 4 (Appendix O) summarizes the statistical findings of the measures of self-efficacy obtained from participants in the project. When considering only statistically significant increases in self efficacy (unidirectional), self efficacy was significantly increased for measures of "eating more healthy" and "overeating less often".

\section{Results}

Specific objectives were established in planning for the implementation of this program. Evaluation of the successes of the program can be completed according to these particular objectives. 
The primary objective of the program was that as a result of this practice change, RCPCA would develop and implement a three-session educational program for patients at risk for developing type $2 \mathrm{DM}$. In evaluating this objective, it is noted that the program was successfully implemented as planned with minimal disruption to the daily activities of the facility. Recruitment of individuals presented the greatest obstacle to implementation of the program. However, despite difficulty with recruitment of individuals, once recruited, participants were enthusiastically supportive of the program and would recommend the program to family and friends. This word-of-mouth communication about the program will be beneficial in continuation of the program. Presentation of the results of the program will be made to the medical director and Board of Directors of the organization and approval will be sought to continue the program on a repetitive cycle at least biannually.

The ADA recommends screening for type $2 \mathrm{DM}$ beginning at the age of 45 if a person is overweight. However, in the process of offering the program and screening participants not originally identified in the search process, including those less than 45 years of age, several patients were identified as having IFG and pre-diabetes at a younger age. This raises the concern that younger, at-risk patients are not being tested for type $2 \mathrm{DM}$ in routine medical care. As a result of this observation, health care providers at the organization recognize the need to screen individuals at various ages with other risk factors for type $2 \mathrm{DM}$. This will likely identify more individuals who can benefit from the program. As such, providers are now coding these patients as pre-diabetic or with IFG. This makes the electronic health record an efficient method of identifying individuals to offer the education program.

Financial costs to implement the program are estimated at $\$ 8.40$ per participant with pedometers, and $\$ 3.40$ per participant without incentives such as pedometers (Appendix $\mathrm{P}$ ). The 
program is considered low cost to implement. Given the economic feasibility of the program, it could be offered: free of charge, with a flat fee to participate, or billing could be completed for reimbursement from third party payers. This will be determined in conjunction with the Board of Directors and organization administrator.

Specific goals that were to be achieved from program implementation included:

Goal 1: At least 30 patients who meet inclusion criteria will choose to participate in the program. Despite multiple incentives that were offered, this goal was not met. Only 11 of the original eligible participants opted to begin the program. However, with a more widespread recruitment effort, additional patients were recruited, screened, and included in the program. Other providers in the organization were helpful in recruiting participants and will continue to be important stakeholders and champions as the program is offered in the future. It is hoped that additional providers will recognize the value of the program for patients and that they will invite and strongly encourage their patients to participate.

Goal 2: At least 23 patients who began the program would finish it. Twenty-two of 25 pre-diabetic patients completed the program. All 25 participants completed the three-class program but either did not complete post-program laboratory studies or questionnaires and follow up survey. Nine of 13 guest participants completed the program with four participants attending all classes but being lost to attrition at the time of the 12 week follow up. Participants were contacted once and reminded of needed follow up. Overall, this represents an acceptable attrition rate from the program.

Goal 3: Twelve weeks from the beginning of the intervention $75 \%$ of patients completing the $\underline{\text { SSBR program at RCPCA will demonstrate improvements in one or more of the physiological }}$ parameters that predict risk for type 2 DM including FPG, weight, BMI, blood pressure, LDL 
cholesterol, triglycerides, and HDL cholesterol. Summary statistics have already been presented but statistically significant reductions $(p<.000)$ in FBG, weight, BMI, and systolic BP were noted in the group. Specific weight loss goals established at the onset of the program included: $75 \%$ of patients completing the SSBR program at RCPCA will lose two to five percent of baseline, total body weight. As noted, $82 \%$ of participants were able to lose at least two percent of body weight.

Goals were set for lifestyle modifications related to exercise and it was hoped that $90 \%$ of the patients completing the SSBR program at RCPCA would demonstrate an increase in either exercise intensity or frequency of exercise by the conclusion of the program. Only $54.5 \%$ of the group reported being able to increase either frequency or intensity of exercise with intensity increases more likely than frequency. However, several participants were already engaged in regular exercise regimens at the onset of the program. When evaluating and considering these participants' baseline level of exercise, $81.8 \%$ were able to maintain or increase the intensity and frequency of exercise with ten of 22 participants reporting moderate exercise on three to five or six to seven days of the week at the 12-week follow up.

Self efficacy measurements were obtained with questionnaires included in the Power to Prevent curriculum and the pre-program goal was that $90 \%$ of the patients completing the SSBR program at RCPCA will demonstrate increased self-efficacy in lifestyle modifications including healthier eating and increasing physical exercise. Review of the data shows that for this group, they were most successful at making improvements with dietary measures by reducing dietary fat $(72.7 \%)(p=.014)$ and overeating less often $(63.6 \%)(p=.007)$ while $50 \%$ of participants reported making positive changes related to reductions in skipping meals and then overeating $(p=.145)$ Table 5 (Appendix Q) summarizes the changes in lifestyle modifications of the group. 
In order to elicit feedback at the conclusion of the entire program, a post-program survey (Appendix L) was anonymously completed by participants. Specific comments from the 12-week post-program survey were obtained from participants related to the program and included:

- This was a great program. It helped me to become more active. I walk daily now. Have lost 25 pounds, my blood pressure is better and I feel great. Now I look at the nutrition facts on food when I shop. I never did this before. I count my fat and calories. This has been one of the best things I could have done. Without Lisa having this program I am sure I would still be overeating, not making healthy choices and not being physically active. Thanks.

- I would have never walked in a 5K-this has motivated me more-hope we can do it again in the future.

- Meeting weekly was wonderful encouragement to "stay on the plan". Also, if I hadn't had a "walking buddy" during lunch then I wouldn't have been as successful.

- The biggest help was the weekly group sessions.

- It needs more classes but other than that I think it helped me a lot.

- The program was wonderful. A few extra group meets would have been welcome.

- Good program learned a lot.

- I really began the program well. Then school started...I had surgery...got sick: every excuse... However it did help and I am still trying.

- It was good to meet together and not feel pressured but provided with help!

- Meeting weekly with the group might help to keep more people motivated.

- I think it was fine the way it is with someone calling to check with me and I really did like the class. It really helped motivate me. 
- Thank you! This has been very helpful.

\section{Analysis of Program Success}

The implementation of this practice change was deemed successful given the statistically significant results in physiological parameters as well as self-efficacy measures. In evaluating the practice change and its success, it becomes important to evaluate potential reasons for that success and potential biases that may have occurred, skewing the results. Five participants were able to lose ten percent or more of their body weight, ranging from 22 to 28 pounds. It becomes important to evaluate the personal characteristics of these participants for common threads that may have contributed to their success. Three were women and two were men with representation from each of the three classes (three from the initial offering and one each from subsequent offerings). Three brought guests to the program and two did not. Four were married and one was not. All had tried to lose weight before and only one had experienced significant weight loss before ( 40 pounds, only to re-gain the weight). One was started on levothyroxine during the program for treatment of hypothyroidism. Levothyroxine is intended to replace a deficiency of thyroid hormone in the body and by effects on metabolism, may contribute to weight loss. Two were patients of the project director and the remaining three were patients of other providers in the organization. Overall, no common threads were noted among these highly successful participants.

Attendance at each class was good and attrition was relatively low. A bias towards attendance and participation may have been created affecting the group at the Ritchie High School site given that the principal was instrumental in setting the program up there and encouraging participation for staff. Only one of the highly successful participants attended at this site. A potential bias towards attendance and participation may have been created at the Pleasants 
County site given the small community and familiarity of the project director with some participants. Only one of the highly successful participants attended at this site.

Given that three of the five highly successful participants completed the program at the RCPCA site in late October it bears consideration that timing of the program may have adversely affected outcomes. It was hoped that the program could be implemented by summer and conclude with participation in the $5 \mathrm{~K}$ walk/run in early August. It was hoped that this timing could be beneficial in helping participants to meet exercise goals with extended daylight hours and warmer weather. However, the subsequent groups did not conclude their programs until midDecember, between holidays and with cooler, darker conditions. There is a theoretical potential that there might be even greater success in outcomes if the program could be implemented earlier in the year.

\section{Discussion and Recommendations}

An additional goal established at the onset of this project was that RCPCA would initiate a billable service offering diabetes prevention education in a group setting on an ongoing basis. Given the results of this pilot project, from the physiological parameter changes (FBG, weight, etc), the measures of self-efficacy, and participants' reaction, it is believed that the program can be very economically implemented in a rural primary care practice. While this program was offered at no fee to participants, it is expected that review of the program by the Board of Directors and medical director could present the opportunity for the organization to continue to provide this program as a billable service to patients, thus generating revenue that will help to sustain the intervention. However, it remains to be seen if participants will be willing to pay for a service such as this. Research has shown that patients are willing to pay $\$ 63$ for diabetes prevention programs (Johnson, Manjunath, Mansfield, Clayton, Hoerger, \& Zhang, 2006) and 
the organization may opt to offer the program for a fee. However, in this county, the median household income of the residents is $\$ 28,826$ with $7 \%$ of the households earning less than $\$ 10,000$ per year. Estimates place the poverty level at $23.1 \%$ for all ages with $13.8 \%$ of the total population without health insurance (Denas-Walt, Proctor \& Smith, 2008) and the most recent unemployment rate at 11.5\% (Unemployment in the Mid-Ohio Valley, 2009), up from a level of 5.1\% in 2000 (US Census Bureau, 2000). If response to a reimbursable program is minimal, the implementation costs are such that the program could be offered with as little as a five-dollar fee to cover program expenses. It is believed that many patients would be able to afford this amount while offering a needed service to the at-risk population. An important option to consider given these statistics would be to obtain grant funding for the program. Multiple grant opportunities exist for preventive therapies and health promotion that would support expansion of the program to include more classes, the inclusion of structured exercise classes, or other incentives such as temporary gym memberships for participants all designed to offer incentives for participation and tools for patient use to help them achieve their weight loss and exercise goals.

Based on the recommendations of participants, the program could be offered to other groups of individuals. Included in suggestions by participants was that the program be offered to adolescents or at work sites. The school based health centers provide another forum for program implementation which was already encouraged by members of the board of directors prior to this program's implementation.

Many studies conducted to evaluate the impact of lifestyle interventions on type 2 DM prevention are successful in demonstrating excellent results initially but maintenance of that lifestyle intervention with behavior change has proved to be more difficult for participants (Madden, Loeb, \& Smith, 2008). Although the effect declines, risk reduction for the 
development of type 2 DM years after study completion is still evident from follow up analysis of data collected and is still greater when compared to those persons who were not exposed to the intervention. One cannot say with certainty risk reduction is truly due to the intervention or other factors that occur the longer the time from when the intervention was implemented. It is evident from the literature that contact and follow up with healthcare professionals increases the likelihood of sustained engagement and adherence to the lifestyle intervention. It remains unclear, however, as to the recommendations for the method, frequency, and timing of that follow up. For this program, contact could be made twice yearly to follow up on patients. This follow up could be via telephone, letter, or even electronic mail, the latter of which would add no cost to the program's implementation. Participants could be personally invited to participate in the organization's $5 \mathrm{~K}$ health walk/run each year. The electronic medical record is also capable of providing pop-up reminders that could alert staff to SSBR participation and encourage dialogue related to continuation of lifestyle modifications. As more group classes are initiated, participants who have been successful with the program could be invited to return to address new classes and relate success stories as well as trials and pitfalls in their personal experiences.

While the program stresses setting/establishing small achievable goals each week, data from the post-program survey (Appendix R) showed that almost half of participants rarely wrote weekly goals (zero to two weeks only) while an additional $34 \%$ wrote goals only three to four weeks of the 12-week program. This could represent a difficulty with participants' ability to formulate objective, measurable, realistic goals; or a perceived lack of importance for this activity. It would be important with future programs to include more of an emphasis on goal setting with participants and possibly include goal sharing with the group in a more formal manner. 
Recording dietary intake has been shown to be the most effective strategy for success with weight loss programs and is stressed with the SSBR program. When surveyed, 39\% of participants felt that recording dietary intake was "very difficult" or "somewhat difficult". It would be important to offer more practice in completing dietary logs during class sessions so that participants feel more comfortable with this activity.

While the data collected demonstrated that three weekly meetings combined with telephone follow up is effective at increasing self efficacy and promoting weight loss and lifestyle modifications to improve health, participants from each group had mixed reactions with the limited number of class meetings. More than one participant expressed a desire to meet weekly throughout the 12 week program while several more participants requested additional classes throughout the 12 week program but not necessarily weekly. It seems reasonable to elicit group consensus for future classes as to the number and frequency of classes. Implementing the program with three biweekly classes may also be an option that class participants might consider. This format would allow participants to implement and achieve mastery of the curriculum from each class before moving on to subsequent information.

Since initiating this program, the recommendation of experts for screening for diabetes and pre-diabetes has changed to include the glycosolated hemoglobin, or hemoglobin A1c level, as an alternate diagnostic test to FBG or glucose tolerance test (ADA, 2010). Hemoglobin A1c levels of 5.7 to 6.4 percent will be used to indicate a diagnosis of pre-diabetes with diabetes diagnosed at 6.5 percent or higher. Therefore, providers at RCPCA would be encouraged to evaluate the A1c for at risk patients, considering risk factors other than age and screening those with family history, genetic predisposition, gestational diabetes, and/or obesity regardless of age. Additionally, patients who express a desire to lose weight or simply cook or eat more healthfully 
for themselves and their families could also be offered the program regardless of blood glucose status.

\section{Conclusion}

Diabetes, specifically type $2 \mathrm{DM}$, is reaching epidemic proportions in this country as well as worldwide. Research has demonstrated that the risk to developing type 2 DM can be significantly reduced or at least delayed with the incorporation of modest increases in activity and modest changes in eating patterns. It becomes important that education be given to at-risk individuals as to the benefits of small changes in lifestyle. This practice change project is based, in part, on the recommendations of experts for interventions and education designed to empower individuals to make those modest changes. This project demonstrated the translation of evidenced based practice change into a cost-effective, real world program that was capable of producing positive results in physiological parameters, as well as measures of self efficacy, and the incorporation of lifestyle modifications to lower risk for patients. Group delivery of information was an efficient and cost-effective method of dissemination of information. Follow up contact with participants was viewed as beneficial by participants. The project was in congruence with the mission and vision of the organization and is expected to be continued at RCPCA. 


\section{References}

Ackerman, R. T. \& Marrero, D. G. (2007). Adapting the Diabetes Prevention Program lifestyle intervention for delivery in the community. The Diabetes Educator, 33(1), 73-78.

Aldana, S., Barlow, M., Smith, R., Yanowitz, F., Adams, T., Loveday, L., \& Merrill, R. M. (2006). A workplace diabetes prevention program: Two-year impact on health. American Association of Occupational Health Nurses, 54(9), 389-395.

American Association of Clinical Endocrinologists. (2007). American Association of Clinical Endocrinologist's medical guidelines for clinical practice for the management of diabetes mellitus. Prevention of Type 2 diabetes mellitus. Endocr Pract May-June;13(Suppl 1): 13-16.

American Diabetes Association. (2008a). Standards of medical care in diabetes. Diabetes Care, 31, supp.1, S12-S54.

American Diabetes Association. (2008b). Standards of medical care in diabetes. IV. Prevention of Type 2 diabetes. Diabetes Care, Jan;31(Suppl 1):S15-6.

American Diabetes Association. (2009). Summary of revisions for the 2010 clinical practice recommendations. Retrieved February 10, 2010 from http://care.diabetesjournals.org/content/33/Supplement_1/S3.full

Amundson, H. A., Butcher, M. K., Gohdes, D., Hall, T. O., Harwell, T. S., Helgerson, S. D., \& Vanderwood, K. K. (2009). Translating the Diabetes Prevention Program into Practice in the General Community. The Diabetes Educator, 35(2), 209-222.

Bandura, A. (1997). Self-efficacy: The exercise of control. New York: Freeman.

Burnet, D. L., Elliott, L. D., Quinn, M. T., Plaut, A. J., Schwartz, M. A., \& Chin, M. H. (2005). Preventing diabetes in the clinical setting. Journal of General Internal Medicine, 21, 84- 
93.

Centers for Disease Control and Prevention. (2006). U.S. physical activity statistics: definitions.

Retrieved April 1, 2009 from

http://www.cdc.gov/mccdphp/dnpa/physical/stats/definitions.htm

Centers for Disease Control and Prevention. (2007a). National diabetes fact sheet: General information and national estimates on diabetes in the United States. Retrieved March 1, 2009 from http://apps.need.cdc.gov/DDTSTRS/FactSheet.aspx

Centers for Disease Control and Prevention. (2007b). West Virginia: Summary of physical activity. Retrieved March 1, 2009 from http://apps.nccd.cdc.gov/PASurveillance/StateSumResultV.asp

Centers for Disease Control and Prevention. (2008a). Deaths: Preliminary data for 2006. Retrieved April 11, 2009 from http://www.cdc.gov/nchs/data/nvsr/nvsr56/nvsr56 16.pdf.

Centers for Disease Control and Prevention. (2008b). Press release: Number of people with diabetes increases to 24 million. Retrieved March 1, 2009 from http://www.cdc/gov/media/pressrel/2008/r080624.htm

Centers for Disease Control and Prevention. (2009). Physical activity for a healthy weight. Retrieved June 29, 2009 from http://www.cdc.gov/healthyweight/physical_activity/index.html.

Cox, K. L., Burke, V., Morton, A. R., Beilin, L. J. \& Puddey, I. B. (2004). Independent and additive effects of energy restriction and exercise on glucose and insulin concentrations in sedentary overweight men. American Journal of Clinical Nutrition, 80, 308-316.

Denas-Walt, C., Proctor, B. D., \& Smith, J. (2008). Income, poverty and health insurance coverage in the United States: 2007. Retrieved March 1, 2009 from http://www.census.gov/prod/2008pubs/p60-235.pdf

Diabetes Prevention Program Research Group. (1999). The Diabetes Prevention Program: 
Design and methods for a clinical trial in the prevention of Type 2 diabetes. Diabetes Care, 22(4), 623-634.

Finnish Medical Society Duodecim. (2006). Physical activity in the prevention, treatment, and rehabilitation of diseases. EBM Guidelines, Helsinki, Finland: Wiley Interscience. John Wiley \& Sons; Dec 22.

Gillies, C. L., Abrams, K. R., \& Lambert, P. C. (2007). Review: Lifestyle or pharmacologic interventions prevent or delay Type 2 diabetes in people with impaired glucose tolerance. Evidence Based Nursing, 10. Retrieved March 15, 2008, from ebn.bmj.com.

Jeon, C. Y., Lokken, R. P., Hu F. B., \& van Dam, R. M. (2007). Physical activity of moderate intensity and risk for Type 2 diabetes. Diabetes Care, 30, 744-752.

Jones, F. (2006). Strategies to enhance chronic disease self-management: How can we apply this to stroke. Disability and Rehabilitation, 28(13-14), 841-847.

Johnson, R. F., Manjunath, R., Mansfield, C. A., Clayton, L. J., Hoerger, T. J., \& Zhang, P. (2006). High-risk individuals' willingness to pay for diabetes risk-reduction program. Diabetes care, 29(6), 1351-1356.

Lev, E. L. \& Owen, S. V. (2000). Counseling women with breast cancer using principles developed by Albert Bandura. Perspectives in Psychiatric Care, 36(4), 131-138.

Lindstrom, J., Peltonen, M., \& Tuomilehto, J. (2005). Lifestyle strategies for weight control: Experience from the Finnish Diabetes Prevention Study. Proceedings of the Nutrition Society, 63, 81-88.

Madden, S. G., Loeb, S. J., \& Smith, C. A. (2008). An integrative literature review of lifestyle interventions for the prevention of Type 2 diabetes mellitus. Journal of Clinical Nursing, 
17(17), 2243-2256.

Morrato, E. H., Hill, J. O., Wyatt, H. R., Ghushchyan, V. \& Sullivan, P. W. (2007). Physical activity in U.S. adults with diabetes and at risk for developing diabetes, 2003. Diabetes Care, 30(2), 203-209.

National Diabetes Education Program. (2005). Small Steps. Big Rewards. Your Gameplan for Preventing Type 2 Diabetes: Executive Summary. Retrieved April 1, 2009 from http://www.ndep.nih.gov/diabetes/pubs/GP booklet.pdf National Guidelines Clearinghouse. (2010). Rating scheme for the strength of recommendations: Retrieved February 10, 2010 from www.guidelines.gov.

Nield, L., Summerbell, C. D., Hooper, L., Whittaker, V., \& Moore, H. (2008). Dietary advice for the prevention of type 2 diabetes mellitus in adults. Cochrane Database of Systematic Reviews, Issue 3. Art. No.: CD005102. DOI: 10.1002/14651858.CD005102.pub2.

Nieuwhenhuijsen, E.R., Zemper, E., Miner, K., \& Epstein, M. (2006). Health behavior change models and theories contributions to rehabilitation. Disability and Rehabilitation, 28(5).

Norris, S. L., Zhang, X., Avenell, A., Gregg, E., Schmid, C. H., Lau, J. (2005). Long-term nonpharmacological weight loss intervention for adults with prediabetes. Cochrane Database of Systematic Reviews. Issue 2. Art. No.: CD005270. DOI: 10.1002/14651858.CD005270.

Orozco, L. J., Buchleitner, A. M., Gimenez-Perez, G., Roque I Figuls, M., Richter, B., \& Mauricio, D. (2008). Exercise or exercise and diet for preventing Type 2 diabetes mellitus. Cochrane Database of Systematic Reviews, Issue 3. Art. No.: CD003054. DOI: 10.1002/14651858.CD003054.pub3.

Pagoto, S. L., Kantor, L., Bodenlos, J. S., Gitkind, M., \& Ma, Y. (2008). Translating the 
Diabetes Prevention Program into a hospital-based weight loss program. Health Psychology, 27(1), Suppl. S91-S98.

Parrish, T. R., Kosma, M., \& Welsch, M. A. (2007). Exercise training for the patient with heart failure: Is your patient ready? Cardiopulmonary Physical Therapy Journal, 18(3), 12-20.

Polit, D. F. \& Beck, C. (2008). Nursing Research: Generating and Assessing Evidence for Nursing Practice. Lippincott, Williams, \& Wilkins: Philadelphia.

Price, V. \& Archbold, J. (1995). Development and application of social learning theory. British Journal of Nursing, 4(21), 1263-1268.

Resnick, B. (2003). The theory of self efficacy. In M. J. Smith \& P. Middle Range Theory for Nursing, (pp. 49-68). New York: Springer Publishing Company, Inc.

Senecal, C. \& Nouwen, A. (2000). Motivation and dietary self-care in adults with diabetes: Are self-efficacy and autonomous self-regulation complementary or competing constructs. Health Psychology, 19(5), 452-457.

Serrano, E., Leiferman, J., \& Dauber, S. (2007). Self-efficacy and health behaviors toward the prevention of diabetes among high risk individuals living in Appalachia. Journal of Community Health, 32(2), 121-133.

Shortridge-Baggett, L. M. (2001). Self-efficacy: Measurement and interventions in nursing. Scholarly Inquiry for Nursing Practice: An International Journal, 15, 183-188.

Smith, S. L. \& West, R. L. (2006). The application of self-efficacy principles to audiologic rehabilitation: A tutorial. American Journal of Audiology, 15, 46-56.

Throits, P. A. (1995). Stress, coping, and social support processes: Where are we? What next? Journal of Health and Social Behavior, (Special Issue), 53-79.

Unemployment in the Mid-Ohio Valley. (2009, March 27). River City Times, p. 4. 
United States Census. (2000). Retrieved: April 2, 2008 from http:/factfinder.census.gov/servelet/QTTable? bm=ky\&geo

U. S. Department of Health and Human Services. (2000). Healthy People 2010: Understanding and improving health. $2^{\text {nd }}$ ed. Washington, DC.

Van der Laar, K. E. \& van der Bijl, J. J. (2001). Strategies enhancing self-efficacy in diabetes education: A review. Scholarly Inquiry for Nursing Practice: An International Journal, $15,235-248$.

Whittemore, R., Melkus, G., Wagner, J., Dziura, J., Northrup, V., \& Grey, M. (2009). Translating the Diabetes Prevention Program to primary care: A pilot study. Nursing research, 58(1), 2-12.

Yamaoka, K. \& Tango, T. (2005). Efficacy of lifestyle education to prevent type 2 diabetes. Diabetes Care, 28(11), 2780-2786.

Zizzi, S., Goodrich, D., Wu, Y., Parker, L., Rye, S., Pawer, V., Mangone, C., \& Tessaro, I. (2006). Correlates of physical activity in a community sample of older adults in Appalachia. Journal of aging and physical activity, 14, 423-438. 


\section{Appendix A}

\section{Letter of Agreement}

The intent of this letter of agreement is to outline the agreement between Ritchie County Primary Care and Lisa Straight, FNP in the completion of the capstone project: Small Steps. Big Rewards to fulfill the requirements of the Doctorate in Nursing Practice (DNP) program at West Virginia University (WVU). The organization agrees to provide the following:

- Use of the facility including equipment such as blood pressure cuffs, scales and kitchen facilities during regular business hours for conducting the educational sessions

- Use of the electronic medical records system to identify potential participants

- Use of the telephone within the facility for use in contacting patients

- Use of nursing personnel/medical assistants to obtain blood pressures, weight and perform venipunctures

- Use of office personnel to direct patients to meeting rooms

- Access to copier for the use of copying program materials

- Waiver of \$10 lab-draw fee for post-intervention labwork

- Waiver of one entry fee per participant for organization's 5K walk/run for August 2010

- Permission to use data collected for publication maintaining patient confidentiality

Lisa Straight, FNP agrees to provide the following:

- Data collection in a manner that maintains HIPPA privacy

- Educational classes at times that do not interfere with regular work hours

- A summary of data collected and outcomes of project

Agreed upon this 8th day of Aupust, 2009.

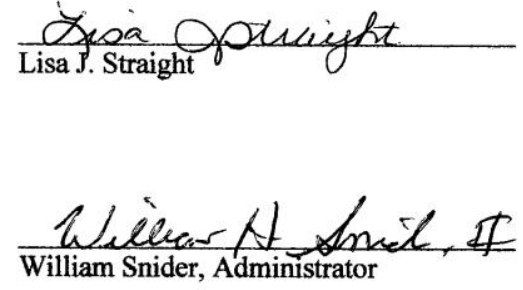


Appendix B

Recruitment Letter

Dear

You are invited to join RCPCA in an effort to prevent diabetes in our community. Risk factors for diabetes include being less active, being overweight, having a family member with diabetes, having diabetes during pregnancy, having high blood pressure, having high fats in the blood and having high sugar in the blood.

Based on the results of your recent bloodwork, you are at risk for diabetes. The good news is that diabetes can be prevented with simple changes in diet and exercise. We at RCPCA would like to invite you to be in a new program we are starting to help you lower your risk for diabetes. This program includes education about diet, exercise and small changes you can make to lower your risk for getting diabetes. The program consists of three 60-90 minute group classes. You may bring a family member with you to the classes if you like. Refreshments will be served.

There is no fee for this program since this is the first time that it is being offered. People who finish this first program will get blood work to check sugar and cholesterol levels at a reduced fee. You will also get a pedometer to measure your walking steps and plates to help you with portion sizes of foods that you eat. When you finish the program you will get a free 2010 entry into the $5 \mathrm{~K}$ walk sponsored by RCPCA and a t-shirt.

Please return your answer in the envelope provided by August 11, 2009. Please call us at 304-643-4005 if you have any questions or would like more information. Thank your for your time and we hope to hear from you soon.

Sincerely,

Lisa Straight

Family Nurse Practitioner 
Name:

Please mark if you will or will not be attending the classes and mail back in the envelope provided. Please mark what class time you prefer. This helps us plan for the classes. Classes will be once a week for 3 weeks. You can change class days if you need. The first class is expected to last 90 minutes while the last 2 are expected to last 60 minutes each.

I am interested in coming to the Small Steps. Big Rewards program at RCPCA. I plan to attend the classes on (mark one)

Tuesday evenings 5-6:30pm: August 18, 25 and September 1

Thursday mornings 9-10:30am: August 20, 27 and September 3

Saturday mornings: 9-10:30: August 15, 22 and 29

I will be bringing a guest: Yes No Please circle one

The best way to contact me is by:

Phone:

Email:

Mail:

No thanks. I am not interested in coming to the Small Steps. Big Rewards program at RCPCA. 


\section{Appendix C}

\section{Advertisement Letter for Newspaper}

Are you 45 years of age or older?

Are you overweight?

Do you have a parent, brother or sister with diabetes?

Did you have diabetes during pregnancy or deliver a baby weighing 9 pounds or more?

Have you ever been told that your blood sugar is higher than normal?

Have you ever been told you have high blood pressure?

Is your cholesterol or triglyceride level high?

Are you physically active less than 3 times per week?

Have you been told you have polycystic ovarian syndrome?

If you answered yes to any of these questions then you are at risk for developing Type 2 diabetes. Diabetes is the leading cause of kidney disease, blindness and non-traumatic amputations in the United States. Approximately 52 million Americans have pre-diabetes and are not even aware. The good news is the Type 2 diabetes can be prevented with simple, small changes in lifestyle.

The Pleasants County School Based Health and Wellness Center at SMHS is sponsoring a program called Small Steps. Big Rewards for patients who are risk for developing Type 2 diabetes. The program will consist of 3 ninety minute group education classes that will give information related to healthy eating, safely beginning an exercise program and weight loss. Participants will be followed for a total of 12 weeks to help them in meeting their goals. There is no cost to participate in this program but space is limited to 25. Participants in the program will receive a pedometer, a portion control plate, and a food diary. Those participants completing the follow up at the end of the 12 weeks will receive a t-shirt and a gift card to a local business.

Classes will be held on Tuesday evenings from 6-7:30pm at the Pleasants County Library. Class dates are September 22, September 29 and October 6. For more information or to register for the program, please call the Wellness Center at 304-684-1216 or Lisa Straight at 304-684-3128 or email at_1_stra@yahoo.com. 
Appendix D

Flyer for Participation

\section{Are you at Risk for Diabetes?}

Are you overweight?

Do you have a parent, brother or sister with diabetes?

Are you 45 years of age or older?

Did you have diabetes during pregnancy or deliver a baby weighing $9 \mathrm{lb}$ ?

Have you ever been told that your blood sugar is higher than normal?

Have you ever been told you have high blood pressure?

Is your cholesterol or triglyceride level high?

Are you physically active less than 3 times per week?

Have you been told you have polycystic ovarian syndrome?

If you answered yes to one or more of these questions, you are at risk for type 2 diabetes. Approximately 52 million Americans have pre-diabetes and are not even aware. The good news is the type 2 diabetes can be prevented with simple, small changes in lifestyle.

The Pleasants County School Based Health and Wellness Center at SMHS is sponsoring a program called Small Steps. Big Rewards for patients who are risk for developing type 2 diabetes. The program will consist of 3 ninety minute group education classes that will give information related to healthy eating, safely beginning an exercise program and weight loss. Participants will be followed for a total of 12 weeks to help them in meeting their goals. There is no cost to participate in this program but space is limited to 25 . Participants in the program will receive a pedometer, a portion control plate, and a food diary. Those participants completing the follow up at the end of the 12 weeks will receive a t-shirt and a gift card to a local business.

Classes are Tuesday evenings from 6-7:30pm at the Pleasants County Library. (Sept 22, Sept 29 and Oct 6. For more information or to register for the program, please call the Wellness Center at 304-684-1216 
Appendix E

Small Steps: Big Rewards at RCPCA Intake Form

Name:

Age:

Sex:

ID \#: Phone:

Mailing Address:

T-shirt size:

Smoking status: Non Current Previous Family hx diabetes: Hx Gestational diabetes:

Current medications:

Meds at conclusion of program:

Have you ever been told not to participate in an exercise program? Yes No

Blood pressure: pre-program: $\mathrm{mmHg}$

Post-program: $\mathrm{mmHg}$

Weight: pre-program:

Post-program:

Height:

Weight and BMI: pre-program

Weight changed:

Post-program:

Baseline measure of exercise: Frequency per week:

Post-intervention measure of exercise: Frequency:

Intensity Duration: Intensity: Duration:

Date of pre-program lab:

Date of post-program labs:

Fasting glucose pre-program: ___ mg/dL Post-program:

Cholesterol: pre-program:

HDL if known: pre-program

Post-program:

Post-program:

Triglycerides if known: pre-program:

LDL: pre-program:

Post-program:

Post-program:

Where am I right now: 1. I eat healthily, 2. I get enough physical activity, 3. I want to eat more healthily, 4. I want to be more physically active

Preprogram: $1 . \quad 2 . \quad 3 . \quad 4$.

Postprogram: 1 . 2 2. 3. 3 . 4 .

How confident are you that you can make changes now?

1. Get physical activity more often 6. Take medications on time

2. Be physically active for a longer time 7. Lose weight if overweight

3. Eat more healthful food

8. Get support from family/friends

4. Overeat less often

9. Get blood pressure under control

5. Miss fewer medications

10. Handle stress better

Preprogram: $1 . \_2$. _ 3 . 3 .

Postprogram: 1.

4.

5

6.

7. 5.

6. 7. 8. 8. 9. 9. 10.

Observations related to self-efficacy:

Attended Session: Date and accompanied by guest (yes or no)

$\# 1$ :

\#2:

\#3: 
Telephone calls: Week 5 date: Week 7 date Week 9 date Week 11 date: Notes: Post-program labs drawn: Date Initiated: Date Completed:

Entry form for $5 \mathrm{~K}$ given:

Date Completed:




\section{Appendix F}

Demographics

Table 1: Age Distribution of Participants

\begin{tabular}{|l|l|}
\hline Age Range for Participant & Number of Participants \\
\hline 20-30 years & $\mathrm{n}=1$ \\
\hline $31-40$ years & $\mathrm{n}=4$ \\
\hline 41-50 years & $\mathrm{n}=10$ \\
\hline $51-60$ years & $\mathrm{n}=7$ \\
\hline
\end{tabular}


Appendix G

Session 1 Worksheet

Are you at risk check-list. Find out if you are at risk for diabetes and pre-diabetes. There are many factors that increase your risk for diabetes. To find out about your risk, check each item that applies to you.

I am 45 years of age or older

I am overweight

I have a parent, brother or sister with diabetes

My family is African American, Hispanic/Latino, American Indian, Asian American or

Pacific Islander

I have had diabetes while pregnant or I gave birth to a baby weighing 9 pounds or more

I have been told my glucose levels are higher than normal

My blood pressure is 140/90 or higher, or I have been told that I have high blood pressure

My cholesterol level levels are not normal. My HDL cholesterol (good) cholesterol is low

$\overline{(<35)}$ or my triglyceride level is high $(>250)$.

I am fairly inactive. I am physically active less than 3 times a week

I have been told I have polycystic ovarian syndrome (POS)

The skin around my armpits appears dirty no matter how I scrub it. The skin appears dark, $\overline{\text { thick }}$ and velvety (acanthosis nigricans)

I have been told that I have blood vessel problems affecting my heart, brain, or legs

Calculate your weight loss goals

5\% weight loss goal: current wt of

$7 \%$ weight loss goal: current wt of $\times 0.05=$

$10 \%$ weight loss goal: current wt of __ $\times 0.1=$ $\times 0.07=$

Estimated time to goal: Estimated time to goal: weeks Estimated time to goal: weeks

Set your calorie and fat gram goals according to the following:

Wt 120-174: fat goal 33 grams and calorie goal 1,200 cal/day

Wt 175-219: fat goal 42 grams and calorie goal 1,500 cal/day

Wt 220-249: fat goal 50 grams and calorie goal 1,800 cal/day

Wt 250+: fat goal 55 grams and calorie goal 2,000 cal/day

SMART (Specific, Measurable, Achievable, Realistic and Timely) Goals for the coming week Please write a goal for yourself for the coming week related to physical activity:

Please write a goal for yourself for the coming week related to healthier eating: 


\section{Appendix $\mathrm{H}$}

\section{Checklist for Class One Content}

Goals: Describe the goals of the Power to Prevent program

Describe the impact that small steps can make in preventing or delaying the development of diabetes

Use tools to take small steps in food choices and in physical activity levels

Identify the difference between a portion and a serving and describe the use of the plate method for controlling portion size

Material needed:

Small Steps. Big Rewards Game plan

Group Participants Guide

Food and Activity Tracker

More than 50 ways to prevent diabetes

Read the food label handout

Energize yourself

Walking: A step in the right direction

Plate method handout

Stretching exercises/Sample walking

Weekly pledge

Getting started with physical activity

Refreshment items

Products for participants:

Portion control plates

Pedometers

Following welcome and introductions

Complete Pre-session 1 Questionnaire. Collect from participants.

What is diabetes? What is pre-diabetes?

Risk factors for developing Type 2 diabetes

How participants were chosen to participate in the program.

What data will be collected for the program. How that data will be used.

Preventing diabetes with diet and exercise

Small Steps. Big Rewards

Setting goals: set goals for the week for diet change, activity change

Strategies for healthy eating

Fat and calorie counters

Portion control. Use of the portion control plate

Importance of physical activity

Use of a pedometer

Food and activity trackers 


\section{Checklist for Class Two Content}

Goals: Describe the importance of choosing healthy foods. Identify ways used in the last week where more healthy foods were substituted. Identify ways that exercise have been or can be incorporated in the daily activities.

Material needed: Lower cholesterol

Healthy eating out/Buffets

Eating out calorie guides

Choose heart healthy foods

Improving your eating habits

Physical activity for a healthy weight

Healthy eating for a healthy weight

Refreshment items

Products for participants:

Following welcome:

Ask for questions regarding content from previous class

Review food and activity logs from week

Ask about problems encountered with food and activity logs

Ask about methods of exercise completed in the last week

Ask about goals set and achieved for diet changes and exercise

Benefits of exercise

How can you increase your physical exercise in healthy ways

What is the best exercise to do?

Low cost, convenient exercises

Compare exercises for calorie expenditures

Ask for information on resources for exercise and diet support in the county/area (TOPS)

Discuss ways to keep from getting discouraged when trying to increase physical activity

Do gentle stretching exercises

Parts of a food label

Saturated fats, trans fats, monounsaturated fats, cholesterol

Healthy alternatives: snacks, drinks

Balancing caloric intake with calorie needs

Set goals for exercise and diet changes for the next week

Ask participants to bring in a healthy recipe for next week: favorite that can be altered to be healthier 


\section{Checklist for Class Three Content}

Goals: Incorporate healthy eating into daily routines

Substitute more healthy foods for less healthy foods

Plan meals that are low cost, healthy

Identify ways to partner with friends and family for physical activity

Recognize stress and negative feelings

Cope with feelings and stress in a positive way

Change negative thoughts into positive feelings

Material needed: 101 tips for family fun

Money saving tips

Tips for busy families

Small Steps

Calendar for month

Coping with bad feelings

Stress

Talking back negative thoughts

Resources in the community

Products for participants: Entry form for $5 \mathrm{~K}$ walk/run

Order for repeat labwork

Refreshments:

Ask for questions regarding content from previous class

Review food and activity logs from week

Ask about problems encountered with food and activity logs

Ask about methods of exercise completed in the last week

Ask about experiences for eating out from this last week

Review meal planning for healthy eating

Ask participants to share healthy recipes

Ways to involve family and friends in lifestyle changes

Have participants create a calendar for listing activities to do with family or individually

Discuss denial, depression, anger, feeling stressed out

Healthy choices for eating out activity

Special occasions: Holidays, parties

Discuss ways of continuing with activity and dietary changes

Discuss follow up labwork and cholesterol values: HDL vs LDL

Complete post-intervention questionnaire

Complete satisfaction survey

Set appointments for follow up labwork 
Appendix I

\section{Pre-Session 1 Questionnaire}

Name or other identifier (such as initials with day and month of birth):

Welcome to our program! You are asked to fill out this questionnaire so that you will be able to see the amount change in your attitudes, lifestyles, and behaviors from the time you start this program (right now) to the time you finish the program. You will compare your answers on this questionnaire with a similar questionnaire you will complete at the end of the program to see how well you are achieving your goals. If you do not want to write your name on this questionnaire, use another identifier, such as the first letters of your first and last names and your day and month of birth (for example, MR 12/17),so that the program leader can return the questionnaire to you at the end of the program. Please use the same identifier for every questionnaire you complete during the program so that all of your questionnaires can be returned to you.

Be Honest in Your Answers. This is for You!

\section{Goals and Expectations}

My goals are to: (Please check all that apply, or write in your own.)

O Lose weight

O Feel better about myself

O Be more physically active

O Learn to eat and/or cook more healthily

O Prevent diabetes in myself and/ or my family

Other:-

My expectations are that I will: (Please check all that apply, or write in your own.)

O Learn more about diabetes control

O Learn more about diabetes prevention

$\mathrm{O}$ Gain support from other members of the group

$\mathrm{O}$ Be able to teach my family about diabetes prevention

$\mathrm{O}$ Be able to make changes in my eating

$\mathrm{O}$ Be able to make changes in my physical activity Other:

NDEP Power to Prevent 


\section{Appendix J \\ Self Efficacy Measures}

Where Am I Right Now?

Thinking about your physical activity and eating over the past three months, please answer the following questions.

Please circle one number to indicate how strongty you agree or disagree with the following statements. (Check "Don't know or refused" if you do not know or do not want to answer.)

Right now:

\begin{tabular}{|l|c|c|c|c|c|c|}
\hline 1. I eat heaithily. & 5 & 4 & 3 & 2 & 1 & \\
\hline 2. I get enough physical activity. & 5 & 4 & 3 & 2 & 1 & \\
\hline 3. I want to eat more heaithily. & 5 & 4 & 3 & 2 & 1 & \\
\hline 4. I want to be more physically active & 5 & 4 & 3 & 2 & 1 & \\
\hline
\end{tabular}

\section{Physical Activity}

Please answer the following questions about your level of physical activity.

During the past week, what was the highest level of physical activity you got? (Check the best answer below.)

Jo specific physical activity routine (just activities of daily living such as walking in the house or at work)

Light intensity physical activity (for example, slowly walking the dog, breathing and heart beat are not faster

j. Moderate intensity physical activity (brisk walking, light yard work e.g. raking leaves or mowing lawn, biking at a casual pace)

[] Vigorous physical activity (jogging/running, swimming laps, playing basketball or soccer)

During the last week, how many days were you physically active at the level you checked above for at least 30 minutes per day?
[1) None
1 to 2 days
3 to 5 days
6 to 7 days

\section{Eating}

Please answer the following question about your eating.

How do you usually decide what to eat? (Please check all that apply.)

Count calories

Count carbohydrates

[.] Avoid sweets and sugars

Limit amount of fat

Eat anything I want or whatever is convenient

Other: 
Please answer the following. Circle only one number for each question. (Check "Don't know or refused" if you do not know or do not want to answer.)

\begin{tabular}{|l|c|c|c|c|c|c|}
\hline & $\begin{array}{c}\text { Daily or } \\
\text { more } \\
\text { often }\end{array}$ & $\begin{array}{c}\text { More often } \\
\text { than weekly } \\
\text { but less than } \\
\text { daily }\end{array}$ & Weekly & $\begin{array}{c}\text { More often } \\
\text { than monthly } \\
\text { but less } \\
\text { often than } \\
\text { weekly }\end{array}$ & $\begin{array}{c}\text { No more } \\
\text { often than } \\
\text { once a } \\
\text { month }\end{array}$ & $\begin{array}{c}\text { Don't } \\
\text { know or } \\
\text { refused }\end{array}$ \\
\hline $\begin{array}{l}\text { 1. How often do you skip a meal } \\
\text { and then snack or overeat? }\end{array}$ & 5 & 4 & 3 & 2 & 1 & 1 \\
\hline $\begin{array}{c}\text { 2. How often do you eat foods high } \\
\text { in fat, such as fried foods or lots } \\
\text { of butter, cheese, or lard? }\end{array}$ & 5 & 4 & 3 & 2 & & \\
\hline 3. How often do you eat more than \\
you think you should?
\end{tabular}

\section{How confident are you that you can make changes now?}

Please circle one number to indicate how confident you are that you can make the following changes. (Check "Don't know or refused" if you do not know or do not want to answer.)

\begin{tabular}{|l|c|c|c|c|c|}
\cline { 2 - 6 } \multicolumn{1}{c|}{ Physical Activity } & Sure I can & Think I can & $\begin{array}{c}\text { Not sure I } \\
\text { can }\end{array}$ & $\begin{array}{c}\text { Don't think } \\
\text { I can }\end{array}$ & $\begin{array}{c}\text { Don't know } \\
\text { or refused }\end{array}$ \\
\hline 1. Get physical activity more often & 4 & 3 & 2 & 1 & \\
\hline 2. Be physically active for longer time & 4 & 3 & 2 & 1 & \\
\hline
\end{tabular}

\begin{tabular}{|l|c|c|c|c|c|}
\cline { 2 - 6 } \multicolumn{1}{c|}{ Eating } & Sure I can & Think I can & $\begin{array}{c}\text { Not sure I } \\
\text { can }\end{array}$ & $\begin{array}{c}\text { Don't think } \\
\text { I can }\end{array}$ & $\begin{array}{c}\text { Don't know } \\
\text { or refused }\end{array}$ \\
\hline 3. Eat more healthful food & 4 & 3 & 2 & 1 & \\
\hline 4. Overeat less often & 4 & 3 & 2 & 1 & \\
\hline
\end{tabular}

\begin{tabular}{l|l|c|c|c|c|}
\cline { 2 - 6 } & Suking Medication \\
(if Applicable) & Sure & Think I can & $\begin{array}{c}\text { Not sure I } \\
\text { can }\end{array}$ & $\begin{array}{c}\text { Don't think } \\
\text { I can }\end{array}$ & $\begin{array}{c}\text { Don't know, } \\
\text { refused or } \\
\text { not taking } \\
\text { medications }\end{array}$ \\
\hline 5. Miss fewer medications & 4 & 3 & 2 & 1 & \\
\hline 6. Take medications on time & 4 & 3 & 2 & 1 & \\
\hline
\end{tabular}

\begin{tabular}{l} 
General Health \\
\cline { 2 - 7 } \\
\begin{tabular}{|l|c|c|c|c|c|}
\hline S. Lose weight if overweight & 4 & 3 & 2 & 1 & \\
\hline 8. Get support from family/friends & 4 & 3 & 2 & 1 & \\
\hline 9. Get blood pressure under control & 4 & 3 & 2 & 1 & \\
\hline 10. Handle stress better & 4 & 3 & 2 & 1 & \\
\hline
\end{tabular}
\end{tabular}

Please put your name (or your initials with day and month of birth) at the top of this questionnaire and give it to your program leader. 


\section{Appendix K}

\section{Small Steps. Big Rewards at Ritchie County Primary Care Satisfaction survey}

Thank you for participating in our program! We hope that you found it helpful.

Please take a minute to complete this satisfaction survey. We will use this information when planning for the next set of classes.

Please rate each of the items below according to the following scale:

How satisfied were you with:

\begin{tabular}{|l|l|l|l|l|}
\hline The number of classes & $\begin{array}{c}\text { Very } \\
\text { satisfied }\end{array}$ & $\begin{array}{c}\text { Somewhat } \\
\text { satisfied }\end{array}$ & $\begin{array}{c}\text { Not } \\
\text { Satisfied }\end{array}$ & $\begin{array}{c}\text { No } \\
\text { opinion }\end{array}$ \\
\hline The times the classes were offered & & & & \\
\hline Information presented & & & & \\
\hline Written materials and handouts & & & & \\
\hline Presentation of information (speaker) & & & & \\
\hline Setting for the classes & & & & \\
\hline Incentives provided (pedometers, plates) & & & & \\
\hline
\end{tabular}

Would you recommend this program to a friend or relative? Yes No

Please include any other comments or suggestions you have about this program. 


\section{Appendix L}

Small Steps. Big Rewards Post Program Survey

In order to plan for future classes, would you please respond to the following statements by circling the response that you feel is most applicable to you. Your responses are completely confidential and will be used only for planning purposes.

1. How often did you use the pedometer to measure your exercise?

Never Rarely Sometimes Frequently Most of the time

2. How easy/difficult did you find it to record your dietary intake (calories and fat) using the Fat/Calorie counter and weekly logs?

Very difficult Somewhat difficult Neutral Easy Very

3. Out of the 12 week period of the program, how many weeks would you say you recorded your calorie/fat intake at least 5 out of 7 days?
$0-2$
3-4
5-6
$7-8$
$9-10$
$11-12$

4. In what form of exercise/activity did you participate in the most frequently?

5. Out of the 12 week period of the program, how many weeks would you say you wrote down a goal to be achieved for that week in your weekly log?
$0-2$
3-4
5-6
$7-8$
9-10
$11-12$

6. How useful were follow up contacts for you in helping you stay motivated?

Very helpful Somewhat helpful Neutral Not particularly helpful

Please provide any suggestions for improvement or comments related to the program that you feel would enhance the program.

Thank you for your time and participation. 


\section{Appendix M}

Table 2: Results of Pre-Session One Questionnaire

\section{Guests Only}

\begin{tabular}{|l|l|}
\hline Goals and Expectations & \# of respondents \\
\hline Lose weight & 10 \\
\hline Learn to eat and/or cook more healthily & 9 \\
\hline Be able to make changes in my eating & 8 \\
\hline Prevent diabetes in myself and/or my family & 10 \\
\hline Be able to make changes in my physical activity & 11 \\
\hline Be more physically active & 11 \\
\hline Feel better about myself & 11 \\
\hline Learn more about diabetes prevention & 6 \\
\hline Learn more about diabetes control & 7 \\
\hline Gain support from other members of the group & 8 \\
\hline Be able to teach my family about diabetes prevention & 5 \\
\hline
\end{tabular}

\section{Participants Only}

\begin{tabular}{|l|l|}
\hline Goals and Expectations & \# of respondents \\
\hline Lose weight & 20 \\
\hline Learn to eat and/or cook more healthily & 19 \\
\hline Be able to make changes in my eating & 20 \\
\hline Prevent diabetes in myself and/or my family & 17 \\
\hline Be able to make changes in my physical activity & 16 \\
\hline Be more physically active & 15 \\
\hline Feel better about myself & 15 \\
\hline Learn more about diabetes prevention & 15 \\
\hline Learn more about diabetes control & 10 \\
\hline Gain support from other members of the group & 9 \\
\hline Be able to teach my family about diabetes prevention & 10 \\
\hline
\end{tabular}


Appendix N

Table 3: Statistical Analysis for Physiological Parameters

\begin{tabular}{|c|c|c|c|c|}
\hline Variable & $\begin{array}{c}\text { Mean } \\
\text { Pre- }\end{array}$ & $\begin{array}{c}\text { Mean } \\
\text { Post- }\end{array}$ & Statistical Test & $\begin{array}{c}\text { Level of } \\
\text { Significance }\end{array}$ \\
\hline Systolic BP (mmHg) & 130.18 & 125.59 & $\begin{array}{c}\text { Paired } t \text { test } \\
\text { one sided } p \text { value }\end{array}$ & .0375 \\
\hline $\begin{array}{c}\text { Diastolic BP } \\
(\mathrm{mmHg})\end{array}$ & 81.09 & 80.27 & $\begin{array}{c}\text { Paired } t \text { test } \\
\text { One sided } p \text { value }\end{array}$ & .311 \\
\hline FBG (mg/dL) & 115.32 & 98.14 & Wilcoxon Signed Ranks Test & .000 \\
\hline Weight (lb) & 221.14 & 211.05 & Wilcoxon Signed Ranks Test & .000 \\
\hline BMI (kg/m2) & 35.31 & 33.45 & Wilcoxon Signed Ranks Test & .000 \\
\hline Total cholesterol & 165.80 & 164.20 & Wilcoxon Signed Ranks Test & .838 \\
\hline HDL cholesterol & 45.10 & 45.30 & Wilcoxon Signed Ranks Test & .767 \\
\hline LDL cholesterol & 98.33 & 95.00 & Wilcoxon Signed Ranks Test & .767 \\
\hline Triglycerides & 206.20 & 199.80 & Wilcoxon Signed Ranks Test & .959 \\
\hline
\end{tabular}


Appendix $\mathrm{O}$

Table 4: Statistical Analysis of Self Efficacy Measures

\begin{tabular}{|l|c|c|c|l|c|}
\hline \multicolumn{1}{|c|}{$\begin{array}{c}\text { Self Efficacy } \\
\text { Variable }\end{array}$} & $\begin{array}{c}\text { Mean } \\
\text { Pre- }\end{array}$ & $\begin{array}{c}\text { Mean } \\
3 \mathrm{wk}\end{array}$ & $\begin{array}{c}\text { Mean } \\
\text { Post- }\end{array}$ & \multicolumn{1}{|c|}{ Statistical Test } & $\begin{array}{c}\text { Level of } \\
\text { Significance }\end{array}$ \\
\hline $\begin{array}{l}\text { Get physically } \\
\text { active more often }\end{array}$ & 3.47 & 3.59 & 3.59 & $\begin{array}{l}\text { Friedman Test } \\
\text { Wilcoxon Signed Rank Test }\end{array}$ & .670 \\
\hline $\begin{array}{l}\text { Be physically } \\
\text { active for longer } \\
\text { time }\end{array}$ & 3.41 & 3.47 & 3.47 & $\begin{array}{l}\text { Friedman Test } \\
\text { Wilcoxon Signed Rank Test }\end{array}$ & $\begin{array}{c}.285 \\
.305\end{array}$ \\
\hline $\begin{array}{l}\text { Eat more healthy } \\
\text { food }\end{array}$ & 1.79 & 2.03 & 2.18 & $\begin{array}{l}\text { Friedman Test } \\
\text { Wilcoxon Signed Rank Test }\end{array}$ & $\begin{array}{c}.00 \\
.090 \text { for change } \\
.045 \text { for increase }\end{array}$ \\
\hline $\begin{array}{l}\text { Overeat less } \\
\text { often }\end{array}$ & 3.35 & 3.41 & 3.59 & $\begin{array}{l}\text { Friedman Test } \\
\text { Wilcoxon Signed Rank Test }\end{array}$ & $\begin{array}{l}.338 \\
.083 \text { for change } \\
\text { for increase }\end{array}$ \\
\hline $\begin{array}{l}\text { Lose weight if } \\
\text { overweight }\end{array}$ & 3.40 & 3.67 & 3.40 & $\begin{array}{l}\text { Friedman Test } \\
\text { Wilcoxon Signed Rank Test }\end{array}$ & .237 \\
.356
\end{tabular}


Appendix $\mathrm{P}$

Projected Budget: Small Steps. Big Rewards.

Non-Funded Project

\begin{tabular}{|c|c|c|c|}
\hline Project Item & Cost & Total & Category Total \\
\hline \multicolumn{4}{|l|}{ Recruitment } \\
\hline Envelopes: Box of 40 x2 & Envelopes & $\$ 2.00$ & \\
\hline \multirow[t]{2}{*}{$\begin{array}{l}\text { Recruitment and acceptance } \\
\text { letters: } 40 \text { postage and copying }\end{array}$} & $\begin{array}{l}\text { Copies: } \$ 0.80 \\
\text { Postage: } \$ 33.60\end{array}$ & $\$ 34.40$ & \\
\hline & & & $\$ 36.40$ \\
\hline \multicolumn{4}{|l|}{ Site } \\
\hline \multirow[t]{2}{*}{ Regular business hours } & $\begin{array}{l}\text { No cost to program or } \\
\text { institution }\end{array}$ & $\$ 0.00$ & \\
\hline & & & $\$ 0.00$ \\
\hline \multicolumn{4}{|l|}{ Program Materials } \\
\hline \multicolumn{4}{|l|}{ Instructor materials } \\
\hline Kit: Power to prevent & $\begin{array}{l}\text { No cost to program or } \\
\text { institution }\end{array}$ & $\$ 0.00$ & \\
\hline Pre-session questionnaire & $\begin{array}{l}40 \text { copies ( } 3 \text { pages/front } \& \\
\text { back) }\end{array}$ & $\$ 1.20$ & \\
\hline Intake form & 40 copies & $\$ 0.40$ & \\
\hline \multirow[t]{2}{*}{ Post-program questionnaire } & $\begin{array}{l}40 \text { copies ( } 3 \text { pages/front } \& \\
\text { back) }\end{array}$ & $\$ 1.20$ & \\
\hline & & & $\$ 2.80$ \\
\hline \multicolumn{4}{|l|}{ Participant materials } \\
\hline Group Participants Guide & 40 copies (front and back) & $\$ 0.80$ & \\
\hline Food and activity tracker & $\begin{array}{l}40 \text { participants x } 9 \text { pages } \times 12 \\
\text { weeks }\end{array}$ & $\$ 43.20$ & \\
\hline $\begin{array}{l}\text { More than } 50 \text { ways to prevent } \\
\text { diabetes }\end{array}$ & 40 copies & $\$ 0.00$ & \\
\hline Read the food label handout & 40 copies $(2$ sided $)$ & $\$ 0.80$ & \\
\hline Lower cholesterol & 40 copies $\times 4$ pages & $\$ 1.60$ & \\
\hline Energize yourself! & 40 copies $\times 8$ pages & $\$ 3.20$ & \\
\hline $\begin{array}{l}\text { Walking: A step in the right } \\
\text { direction }\end{array}$ & 40 copies ( 3 pages) & $\$ 3.20$ & \\
\hline 101 tips for family fitness fun & 40 copies ( 3 pages) & $\$ 3.20$ & \\
\hline Plate method handout & 40 copies $(2$ sided $)$ & $\$ 0.80$ & \\
\hline Healthy eating out/buffets & 40 copies (6 pages) & $\$ 2.40$ & \\
\hline Stretching exercises/Sample & 40 copies (4 pages) & $\$ 1.60$ & \\
\hline
\end{tabular}




\begin{tabular}{|c|c|c|c|}
\hline walking & & & \\
\hline Eating out calorie guides & 40 copies & $\$ 0.00$ & \\
\hline Weekly pledge & 40 copies $\times 4$ sessions & $\$ 3.20$ & \\
\hline $\begin{array}{l}\text { Small Steps. Big Rewards Game } \\
\text { plan }\end{array}$ & 40 copies (21 pages) & $\$ 8.40$ & \\
\hline Money saving tips & 40 copies $(2$ sided $)$ & $\$ 0.80$ & \\
\hline Choose heart healthy foods & 40 copies & $\$ 0.40$ & \\
\hline Tips for busy families & 40 copies & $\$ 0.40$ & \\
\hline Small Steps & 40 copies (3 pages) & $\$ 1.20$ & \\
\hline $\begin{array}{l}\text { Getting Started with Physical } \\
\text { Activity }\end{array}$ & 40 copies ( 3 pages $)$ & $\$ 1.20$ & \\
\hline Improving your eating habits & 40 copies ( 2 sided) & $\$ 0.80$ & \\
\hline $\begin{array}{l}\text { Physical activity for a healthy } \\
\text { weight }\end{array}$ & 40 copies ( 2 sided $)$ & $\$ 0.80$ & \\
\hline $\begin{array}{l}\text { Healthy eating for a healthy } \\
\text { weight }\end{array}$ & 40 copies ( 2 sided) & $\$ 0.80$ & \\
\hline & & & $\$ 78.80$ \\
\hline Incentives & & & \\
\hline Portion control plate & Provided: no cost to program & $\$ 0.00$ & \\
\hline $5 \mathrm{~K}$ entry (one per participant) & Provided: no cost to program & $\$ 0.00$ & \\
\hline Pedometer & 40 at $\$ 5.00$ & $\$ 200.00$ & \\
\hline $\begin{array}{l}\text { T-shirt (one per 5K race } \\
\text { participant) }\end{array}$ & 40 at $\$ 5.00$ & $\$ 200.00$ & \\
\hline $\begin{array}{l}\text { Cups/plates/napkins for } \\
\text { refreshments }\end{array}$ & Donated & $\$ 0.00$ & \\
\hline & & & $\$ 400.00$ \\
\hline Class materials & & & \\
\hline Easel, markers & $\begin{array}{l}\text { Easel provided, markers: } \\
\$ 4.00\end{array}$ & $\$ 4.00$ & \\
\hline Pens & Donated from drug rep & $\$ 0.00$ & \\
\hline & & & $\$ 4.00$ \\
\hline Outcome measures & & & \\
\hline Multichem & $\begin{array}{l}\text { (Deferred draw fee): Pt } \\
\text { assumes cost }\end{array}$ & $\$ 0.00$ & \\
\hline & & & $\$ 0.00$ \\
\hline $\begin{array}{l}\text { Program costs for } \\
\text { implementation }\end{array}$ & For 40 participants & & $\$ 522.00$ \\
\hline
\end{tabular}


Appendix Q

Table 5: Mean Values for Group Eating Habits

\begin{tabular}{|l|c|c|c|c|}
\hline Measurement parameter & $\begin{array}{l}\text { Mean } \\
\text { pre- }\end{array}$ & $\begin{array}{l}\text { Mean } \\
\text { post- }\end{array}$ & Statistical Test & Level of Significance \\
\hline I eat healthily & 2.77 & 3.77 & Wilcoxon Signed Ranks Test & .006 \\
\hline $\begin{array}{l}\text { I get enough physical } \\
\text { exercise }\end{array}$ & 2.36 & 3.14 & Wilcoxon Signed Ranks Test & .32 \\
\hline $\begin{array}{l}\text { Frequency of skipping meal } \\
\text { and then snack or overeat }\end{array}$ & 3.14 & 2.59 & Wilcoxon Signed Ranks Test & .145 \\
\hline Frequency of high fat foods & 3 & 2.54 & Wilcoxon Signed Ranks Test & .014 \\
\hline $\begin{array}{l}\text { Frequency of eating more } \\
\text { than you think you should }\end{array}$ & 3.1 & 2.38 & Wilcoxon Signed Ranks Test & .007 \\
\hline
\end{tabular}


Appendix R

Data from Post Program Surveys

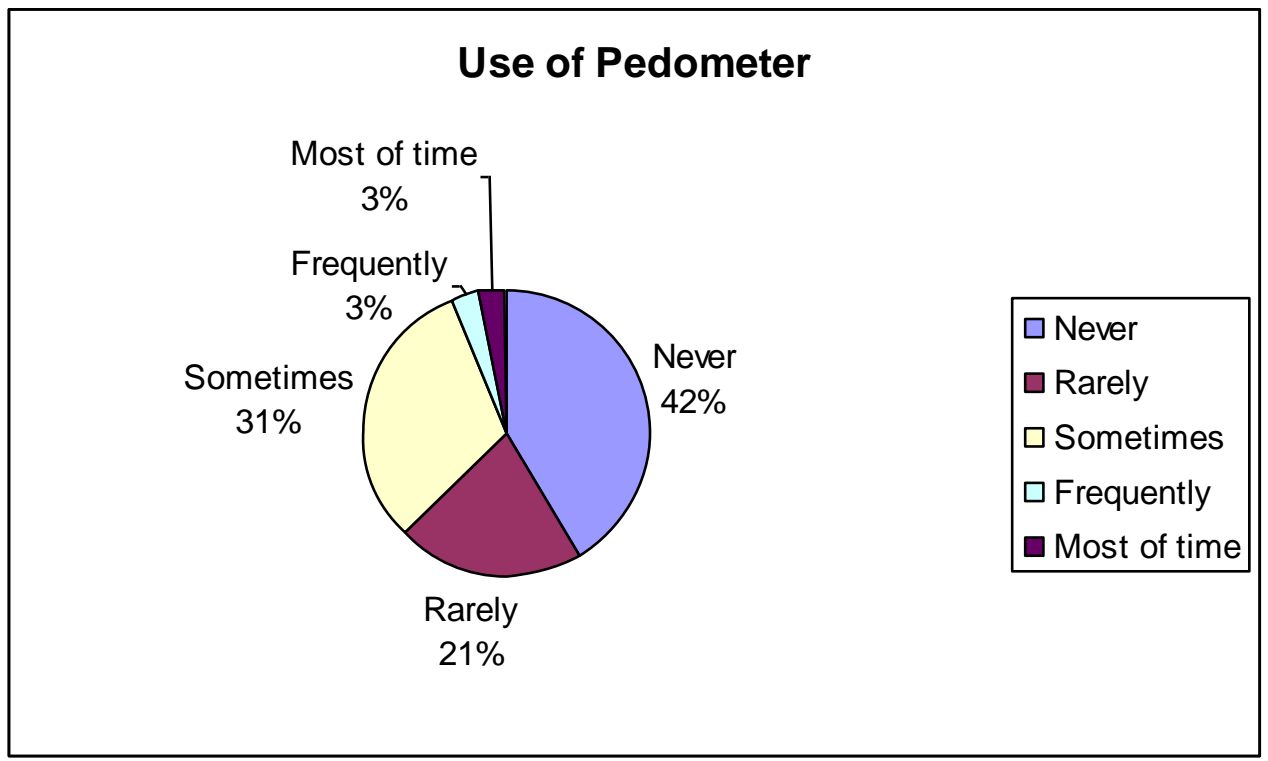

How often did you use the pedometer to measure your exercise?

\section{Ease with Use of Calorie Counter and Logs}

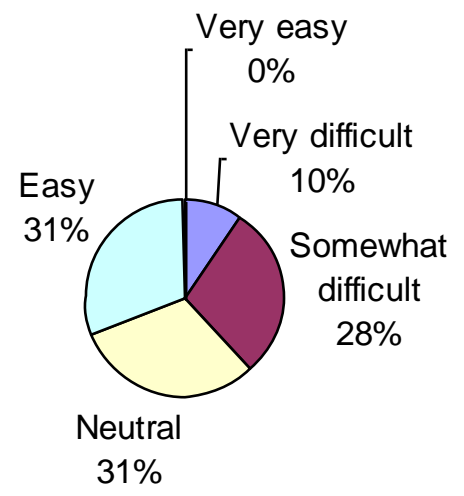

$\square$ Very difficult

$\square$ Somewhat difficult $\square$ Neutral

$\square$ Easy

$\square$ Very easy

How easy/difficult did you find it to record your dietary intake (calories and fat) using the Fat/Calorie counter and weekly logs? 


\section{Weeks Calorie and Fat Intake Recorded 5 of 7 Days}

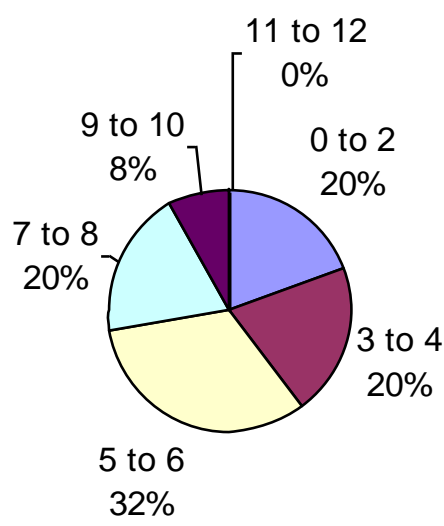

Out of the 12-week period of the program, how many weeks would you say you recorded your calorie/fat intake at least 5 out of 7 days?

\section{Weeks That Goal Was Written}

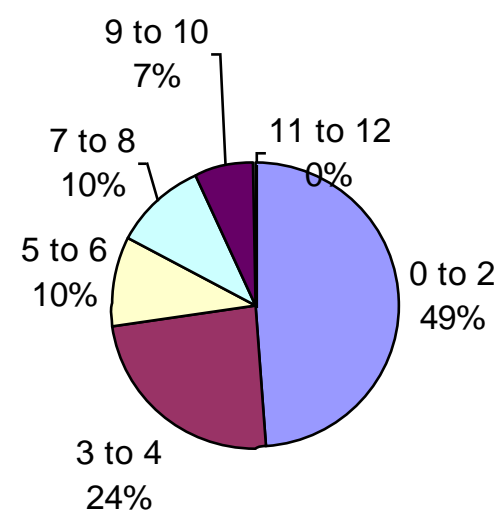

Out of the 12 week period of the program, how many weeks would you say you wrote down a goal to be achieved for that week in your weekly log? 


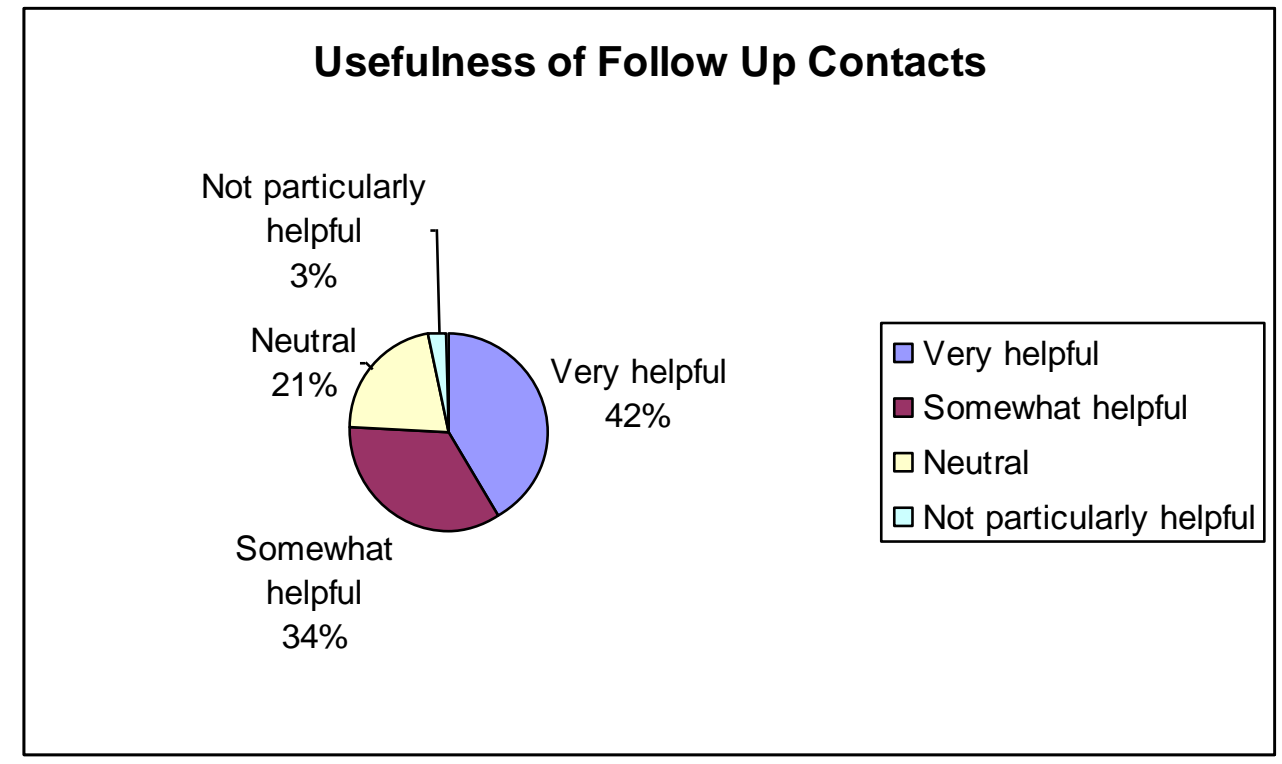

How useful were follow up contacts for you in helping you stay motivated? 